\title{
Overview of AC Motor Sensorless Algorithms: a Unified Perspective
}

This paper was downloaded from TechRxiv (https://www.techrxiv.org).

\section{LICENSE}

CC BY 4.0

SUBMISSION DATE / POSTED DATE

29-09-2021 / 30-09-2021

\section{CITATION}

Chen, Jiahao; Mei, Jie; Zuo, Yuefei; Zhu, Jingwei; Yuan, Xin; Lee, Christopher H. T. (2021): Overview of AC Motor Sensorless Algorithms: a Unified Perspective. TechRxiv. Preprint. https://doi.org/10.36227/techrxiv.16699705.v1

DOI

10.36227/techrxiv.16699705.v1 


\title{
Overview of AC Motor Sensorless Algorithms: a Unified Perspective
}

\author{
Jiahao Chen, Member, IEEE, Jie Mei, Member, IEEE, Yuefei Zuo, Member, IEEE, Jingwei Zhu, \\ Xin Yuan, Member, IEEE, Christopher H. T. Lee, Senior Member, IEEE
}

\begin{abstract}
This paper reviews sensorless algorithms for both induction motors and permanent magnet motors using the active flux model, such that any design applicable for non-salient pole ac motors can also be included in the review framework. The proposed review framework classifies all sensorless algorithms following a five-layer hierarchy abbreviated as O-I-M-A-I, resulting in four main categories as i) inherently sensorless position estimation, ii) non-inherently sensorless position estimation, iii) post-position-estimation speed estimation, and iv) speed estimation for indirect field orientation. Various ac motor models are derived by assuming a constant active flux amplitude, based on which seven generic sensorless algorithms are summarized in a tutorial. Recommendations are made for sensorless drive designers to begin with inherently sensorless method such that the two-way coupling between position estimation and speed estimation is avoided. Finally, classical induction motor model results from time-varying active flux amplitude and slip relation, for which a state transformation is recommended for achieving global stability.
\end{abstract}

Index Terms - self-sensing, active flux, review, induction motor, permanent magnet synchronous motor.

\section{NOMENCLATURE}

The nomenclature we use is common for permanent magnet (PM) motors, where $L_{d}, L_{q}, R, K_{E}$ are respectively $d$-axis inductance, $q$-axis inductance, stator resistance, PM flux linkage. $K_{\text {Active }}=K_{E}+\left(L_{d}-L_{q}\right) i_{d}$ denotes active flux linkage [1] with $d$-axis current $i_{d}=i_{\alpha} \cos \theta_{d}+i_{\beta} \sin \theta_{d}$, and $\theta_{d}$ the angle of active flux vector $\boldsymbol{\psi}_{\text {Active }}=K_{\text {Active }} \angle \theta_{d}$. For induction motors, $L_{d}$ is stator inductance, $L_{q}$ the stator transient leakage inductance, and the inverse- $\Gamma$ rotor flux amplitude dynamics:

$$
\frac{\mathrm{d}}{\mathrm{d} t} K_{\text {Active }}=\frac{-R_{\text {req }}}{L_{d}-L_{q}} K_{\text {Active }}+R_{\text {req }} i_{d}, \quad K_{E}=0
$$

where $R_{\text {req }}$ is inverse- $\Gamma$ circuit rotor resistance [2]. All bold $\mathbb{R}^{2}$ vector symbols are in stator $\alpha \beta$-frame, e.g., $\boldsymbol{i}=\left[i_{\alpha}, i_{\beta}\right]^{\top}$ is the measured $\alpha \beta$-frame current. $\boldsymbol{J}=\left[\begin{array}{cc}0 & -1 \\ 1 & 0\end{array}\right], \boldsymbol{I}=\left[\begin{array}{cc}1 & 0 \\ 0 & 1\end{array}\right]$. Park transformation is $\boldsymbol{P}\left(\theta_{d}\right)=\left[\begin{array}{cc}\cos \theta_{d} & \sin \theta_{d} \\ -\sin \theta_{d} & \cos \theta_{d}\end{array}\right]$. Operator $s=\frac{\mathrm{d}}{\mathrm{d} t}=$.

\section{INTRODUCTION}

Sensorless or self-sensing control is typically referring to the speed regulation of inverter-fed ac motors without using a mechanical sensor for position (e.g., encoder, resolver or hall sensor), or speed (i.e., tachogenerator), which is especially desired for high speed motors (see e.g., [3]), motors with large-diameter or hollow shaft, and motors used in adverse environment [4]. Sensorless algorithm (SA) is at the core of sensorless control, and reconstructs position and speed signals based on the measured current and the model of ac motor.
The model of non-salient (pole) PM motor is a special case of induction motor model [5]. Historically, it is not easy to design SA for salient PM motors, because the positiondependent inductance results in a highly nonlinear model, and the salient PM motor can be treated as a non-salient one if $\left\|\left(L_{d}-L_{q}\right) \boldsymbol{i}\right\| \ll K_{E}[6]$. The active flux concept is proposed in [1] and describes six types of ac motors, including induction motor and salient PM motors. As a matter of fact, in induction motor context, the active flux is no new concept, and is the natural choice of state (i.e., rotor flux) in the inverse- $\Gamma$ circuit of induction motor [7], and it has long been found useful in analysis, e.g., of direct torque control (DTC) [8, Eq. (7)]. In salient PM motor context, active flux has other names in literature, such as fictitious PM flux [9], linear flux [10], and extended flux [11].

The contribution of this paper is to propose an overview framework that reviews SAs for both induction motors and PM motors. The overview has two parts depending on how $K_{\text {Active }}$ is modelled. Sec. II-Sec. $\mathrm{V}$ reviews SAs with constant $K_{\text {Active }}$ assumption. Sec. VI reviews SAs with time-varying $K_{\text {Active }}$ as in (1). The rest of this section builds the foundation to understand the review with a classification and a tutorial.

\section{A. Proposed Classification}

We propose a classification for sensorless algorithms (SAs) that obeys a 5-layer hierarchy, abbreviated as O-I-M-A-I:

1) Output, i.e., position $\hat{\theta}_{d}$ or magnetic field speed $\hat{\omega} \triangleq \dot{\hat{\theta}}_{d}$;

2) Input, i.e., $\boldsymbol{i}$-only, $\hat{\omega}$-dependency, $\hat{\theta}_{d}$-dependency, or $\left(\int \hat{\omega} \mathrm{d} t\right)$-dependency;

3) Model, i.e., voltage model (VM), 2nd-order current, 4thorder emf, 4th-order disturbed flux, motion dynamics;

4) Algorithm, i.e., stabilized voltage model, disturbance observer, state observer, adaptive observer, etc.;

5) Issues and improvements associated with the algorithm. which forms the outline of Sec. I- $\mathrm{W}$ as follows.

- Position Estimation (PE)

- Inherently sensorless (IS) (i.e., no speed anywhere)

* Stabilized VM with flux or voltage compensation Amplitude (i.e. current model) based correction

Angle (i.e., orthogonality) based correction

* Disturbance observer (DO) for emf

Linear DO (that treats ac emf as dc disturbance) Sliding mode (SM) DO

1) Improvement in SM control law: milder switching function and dynamic correction. 
2) improvement in SM surface: incorporation of the integral or the derivative of the current error.

3) improvement in SM gain: reaching law design.

* Saliency based method (invasive and non-invasive)

- Non-inherently sensorless (non-IS) PE ( $\hat{\omega}$ is input)

* Speed is part of model

- EMF observer (full-order and reduced-order)

- Flux observer (full-order and reduced-order)

- Linearization based PE by extended Kalman filter

- Frequency adaptive observer

* Non-IS variants of DO and stabilized VM

- DO for extended emf

- VM utilizing $\hat{\omega}$-dependent orthogonality condition

$d q$-frame variants of DO and VM

* Speed is only used for tuning of DO and VM

- First-order SMDO

1) Chattering issues

2) Ensuing low-pass filter's $\hat{\omega}$-dependency

- Statically compensated voltage model (SCVM)

- Speed estimation

- Post-position estimation (i.e., extract $\hat{\omega}$ from $\hat{\theta}_{d}$ )

* Direct calculation using position, flux, and/or emf

* Inertia-free constant speed adaptation

- Cascaded adaptive observer that has EMF-type, fluxtype, and position-type (i.e., phase-locked loop)

- Speed adaptation law driven by current error

1) Unknown regressor

2) Filtered regressor

* Inertia-free ramp speed tracking

- Extended Kalman filter (EKF)

- Type-3 PLL

* Inertia dependent (i.e., motion dynamics involved)

- Extended Luenberger observer (ELO), extended state observer (ESO), generalized ESO (GESO), generalized proportional-integral observer (GPIO)

Reduced-order natural speed observer

- For indirect field orientation (IFO) (i.e., $\hat{\theta}_{d}=\int \hat{\omega} \mathrm{d} t$ )

* General IFO position estimation

* IFO position based direct calculation with closed-loop

* From magnetic asymmetry (i.e., rotor slot harmonics)

\section{B. Sensorless Control: A Tutorial}

To help understand the classification above, a tutorial on sensorless algorithm (SA) design is now provided.

1) Problem Formulation: Motor's electrical angular rotor speed $\omega_{r}$ is governed by Newton's second law of motion:

$$
\frac{J_{s}}{n_{\mathrm{pp}}} \frac{\mathrm{d}}{\mathrm{d} t} \omega_{r}=T_{\mathrm{em}}-T_{L}
$$

where $J_{s}$ denotes rotor shaft inertia, $n_{\mathrm{pp}}$ designates pole pair number, $T_{L}$ is load torque, and $T_{\mathrm{em}}$ is electromagnetic torque. The sensorless control of system (2) is challenging, because both the inputs $T_{\mathrm{em}}, T_{L}$ and the output $\omega_{r}$ are unknown.

2) The Objective of SAs: The objective of an SA is to estimate $\omega_{r}$ and $T_{\mathrm{em}}$. The latter is proportional to the cross product of the stator flux $\psi_{s}$ and the active flux $\psi_{\text {Active }}$ :

$$
T_{\mathrm{em}}=\underbrace{\frac{3}{2} n_{\mathrm{pp}} L_{q}^{-1} \boldsymbol{\psi}_{s} \cdot\left(-\boldsymbol{J} \boldsymbol{\psi}_{\text {Active }}\right)}_{\text {DTC Formulation }}=\underbrace{\frac{3}{2} n_{\mathrm{pp}} K_{\text {Active }} i_{q}}_{\text {FOC Formulation }}
$$

where the second equal sign is derived by substituting the following relation between $\psi_{s}$ and $\psi_{\text {Active }}$ in $\alpha \beta$-frame [1]

$$
\boldsymbol{\psi}_{\text {Active }} \triangleq K_{\text {Active }} \angle \theta_{d} \equiv K_{\text {Active }}\left[\begin{array}{c}
\cos \theta_{d} \\
\sin \theta_{d}
\end{array}\right]=\boldsymbol{\psi}_{s}-L_{q} \boldsymbol{i}
$$

and $i_{q}=-i_{\alpha} \sin \theta_{d}+i_{\beta} \cos \theta_{d}$ is the $q$-axis current. The FOC formulation in (3) motivates the concept of active flux [1]. Based on (4), the $d$-axis angle $\theta_{d}$ can be extracted by

$$
\begin{aligned}
\theta_{d} & =\arctan 2\left(\psi_{\beta, \text { Active }}, \psi_{\alpha, \text { Active }}\right) \\
\text { or } \theta_{d} & =-\arctan 2\left(\frac{e_{\alpha, \text { Active }}}{\operatorname{sign}\left(\dot{\theta}_{d}\right)}, \frac{e_{\beta, \text { Active }}}{\operatorname{sign}\left(\dot{\theta}_{d}\right)}\right)
\end{aligned}
$$

where $\boldsymbol{e}_{\text {Active }} \triangleq \frac{\mathrm{d}}{\mathrm{d} t} \boldsymbol{\psi}_{\text {Active }}$ is the emf due to active flux.

3) The Main Assumption: From (3), the objective of estimating $T_{\mathrm{em}}$ reduces to estimation of active flux angle $\theta_{d}$, if we assume the active flux amplitude $K_{\text {Active }}$ is a known constant such that both $\alpha$-axis and $\beta$-axis components of $\boldsymbol{\psi}_{\text {Active }}$ are sinusoidal [cf. (44]. Constant $K_{\text {Active }}$ assumption is reasonable for PM motors, and simplifies the design and analysis of SAs for induction motors, which is not well realized in literature.

4) The Models: The estimation of $\theta_{d}$ relies on the dynamics of measured $i$ to reveal $\psi_{\text {Active }}$ or its derivative $\frac{\mathrm{d}}{\mathrm{d} t} \boldsymbol{\psi}_{\text {Active }}$. As per Faraday's law, the stator voltage equation in $\alpha \beta$-frame describes the dynamics among $\boldsymbol{i}, \boldsymbol{\psi}_{\text {Active }}$, and $\boldsymbol{\psi}_{s}$ :

$\frac{\mathrm{d}}{\mathrm{d} t} \boldsymbol{\psi}_{s}=\frac{\mathrm{d}}{\mathrm{d} t}\left(\boldsymbol{\psi}_{\text {Active }}+L_{q} \boldsymbol{i}\right)=\boldsymbol{e}_{\text {Active }}+L_{q} \frac{\mathrm{d}}{\mathrm{d} t} \boldsymbol{i}=\boldsymbol{u}-\boldsymbol{R} \boldsymbol{i}$

where $\boldsymbol{u}$ is $\alpha \beta$-frame voltage. Since there is no speed in (6), the SAs based on (6) are called inherently sensorless [12].

The magnetic field speed $\omega \triangleq \dot{\theta}_{d}$ begins to appear, if we further: i) include the steady state sinusoidal model for either flux or emf: [note differentiating (7a) yields $7 \mathrm{~b}$ ]

$$
\begin{aligned}
\frac{\mathrm{d}}{\mathrm{d} t} \boldsymbol{\psi}_{\text {Active }} & =\omega \boldsymbol{J} \boldsymbol{\psi}_{\text {Active }}+\underbrace{\dot{K}_{\text {Active }}\left[\begin{array}{c}
\cos \theta_{d} \\
\sin \theta_{d}
\end{array}\right]}_{\boldsymbol{E}_{u}, \text { the unmodelled dynamics }} \\
\frac{\mathrm{d}}{\mathrm{d} t} \boldsymbol{e}_{\text {Active }} & =\omega \boldsymbol{J} \boldsymbol{e}_{\text {Active }}+\underbrace{\dot{\omega} \boldsymbol{J} \boldsymbol{\psi}_{\text {Active }}+\frac{\mathrm{d}}{\mathrm{d} t} \boldsymbol{E}_{u}}_{\text {Unmodelled dynamics }} ;
\end{aligned}
$$

or ii) cascade disturbed sinusoidal model for flux estimate [13]:

$$
\frac{\mathrm{d}}{\mathrm{d} t} \hat{\boldsymbol{\psi}}_{s}=\omega \boldsymbol{J}\left(\hat{\boldsymbol{\psi}}_{s}-\boldsymbol{D}_{\psi}\right), \quad \frac{\mathrm{d}}{\mathrm{d} t} \boldsymbol{D}_{\psi} \approx 0
$$

with $\boldsymbol{D}_{\psi} \in \mathbb{R}^{2}$ the low frequency disturbance in stator flux; or iii) substitute (4) into (6) to derive a nonlinear model:

$$
L_{q} s \boldsymbol{i}=\boldsymbol{u}-R \boldsymbol{i}-\omega K_{\text {Active }}\left[\begin{array}{c}
-\sin \theta_{d} \\
\cos \theta_{d}
\end{array}\right], s \omega=0, s \theta_{d}=\omega
$$

or iv) apply Park transformation $\boldsymbol{P}\left(\theta_{d}\right)=\left[\begin{array}{cc}\cos \theta_{d} & \sin \theta_{d} \\ -\sin \theta_{d} & \cos \theta_{d}\end{array}\right]$ to $\left[\begin{array}{ll}6 \\ - \text { : }\end{array}\right.$

$$
\begin{aligned}
\frac{\mathrm{d}}{\mathrm{d} t} K_{\text {Active }}+L_{q} \frac{\mathrm{d}}{\mathrm{d} t} i_{d} & =u_{d}-R i_{d}+\omega L_{q} i_{q} \triangleq e_{d, \mathrm{ss}} \\
\omega K_{\text {Active }} & +L_{q} \frac{\mathrm{d}}{\mathrm{d} t} i_{q}=u_{q}-R i_{q}-\omega L_{q} i_{d} \triangleq e_{q, \mathrm{ss}}
\end{aligned}
$$

where $e_{d, \mathrm{ss}}, e_{q, \mathrm{ss}}$ are steady state emf of $d$ - and $q$-axis. By manipulating inductance, the $d q$-model (10) is rewritten as

$$
\begin{array}{r}
\frac{\mathrm{d}}{\mathrm{d} t} K_{E}+L_{d} \frac{\mathrm{d}}{\mathrm{d} t} i_{d}=u_{d}-R i_{d}+\omega L_{q} i_{q} \\
\underbrace{\omega K_{\text {Active }}-\left(L_{d}-L_{q}\right) \frac{\mathrm{d}}{\mathrm{d} t} i_{q}}_{\text {Amplitude of the extended emf } \boldsymbol{e}}+L_{d} \frac{\mathrm{d}}{\mathrm{d} t} i_{q}=u_{q}-R i_{q}-\omega L_{q} i_{d}
\end{array}
$$


Transforming (11) to $\alpha \beta$-frame gets extended emf $\boldsymbol{e}$ 's model

$$
\begin{gathered}
L_{d} \frac{\mathrm{d}}{\mathrm{d} t} \boldsymbol{i}+\boldsymbol{e}+\omega \boldsymbol{J}\left(L_{d}-L_{q}\right) \boldsymbol{i}=\boldsymbol{u}-R \boldsymbol{i} \\
\frac{\mathrm{d}}{\mathrm{d} t} \boldsymbol{e}=\omega \boldsymbol{J} \boldsymbol{e}+\text { Unmodelled Dynamics }
\end{gathered}
$$

The SAs that are based on (7), (8), (9), (10), (11), or (12) are non-inherently sensorless owing to the presence of $\omega$.

5) Position SA Designs: The model based $\theta_{d}$ estimation can be achieved by the following generic SAs via (5):

SA1: Disturbance observer (DO) for emf using (6):

$$
L_{q} \frac{\mathrm{d}}{\mathrm{d} t} \hat{\boldsymbol{i}}=\boldsymbol{u}-R \hat{\boldsymbol{i}}+\boldsymbol{f}(\tilde{\boldsymbol{i}}), \quad \text { with } \tilde{\boldsymbol{i}} \triangleq \boldsymbol{i}-\hat{\boldsymbol{i}}
$$

where $f(\cdot)$ is correction term to be designed, and emf information is extracted from $\boldsymbol{f}(\tilde{\boldsymbol{i}})$. It is worth pointing out that $\boldsymbol{f}(\cdot)$ can be implemented as dynamic correction ${ }^{1}$

SA2.1: State observer, e.g., using extended emf model (12):

$$
\begin{aligned}
L_{d} \frac{\mathrm{d}}{\mathrm{d} t} \hat{\boldsymbol{i}} & =\boldsymbol{f}_{1}(\tilde{\boldsymbol{i}})+\boldsymbol{u}-R \hat{\boldsymbol{i}}-\hat{\boldsymbol{e}}-\hat{\omega} \boldsymbol{J}\left(L_{d}-L_{q}\right) \hat{\boldsymbol{i}} \\
\frac{\mathrm{d}}{\mathrm{d} t} \hat{\boldsymbol{e}} & =\boldsymbol{f}_{2}(\tilde{\boldsymbol{i}})+\hat{\omega} \boldsymbol{J} \hat{\boldsymbol{e}}
\end{aligned}
$$

where $\boldsymbol{f}_{1}(\cdot), \boldsymbol{f}_{2}(\cdot)$ are corrections to be designed. Similar observer can be constructed for (6) and (7b). Note (14) has its reduced-order variant, e.g., [6]

$$
s \hat{e}=\hat{\omega} \boldsymbol{J} \hat{e}+\boldsymbol{f}(s \hat{\boldsymbol{i}}-s \boldsymbol{i})
$$

where $s \hat{\boldsymbol{i}} \equiv\left[\boldsymbol{u}-R \boldsymbol{i}-\hat{\boldsymbol{e}}-\hat{\omega} \boldsymbol{J}\left(L_{d}-L_{q}\right) \boldsymbol{i}\right] / L_{d}$.

SA2.2: State observer using (6) and (7a):

$$
\begin{aligned}
L_{q} \frac{\mathrm{d}}{\mathrm{d} t} & =\boldsymbol{f}_{1}(\tilde{\boldsymbol{i}})+\boldsymbol{u}-R \hat{\boldsymbol{i}}-\hat{\boldsymbol{\omega}} \boldsymbol{J} \hat{\boldsymbol{\psi}}_{\text {Active }} \\
\frac{\mathrm{d} t}{\mathrm{~d} t} \hat{\boldsymbol{\psi}}_{\text {Active }} & =\boldsymbol{f}_{2}(\tilde{\boldsymbol{i}})+\hat{\omega} \boldsymbol{J} \hat{\boldsymbol{\psi}}_{\text {Active }}
\end{aligned}
$$

Note (16) has its reduced-order variant, e.g., [14]

$$
s \hat{\boldsymbol{\psi}}_{\text {Active }}=\hat{\omega} \boldsymbol{J} \hat{\boldsymbol{\psi}}_{\text {Active }}+\boldsymbol{K}\left[\omega \boldsymbol{J} \boldsymbol{\psi}_{\text {Active }}-\hat{\omega} \boldsymbol{J} \hat{\boldsymbol{\psi}}_{\text {Active }}\right]
$$

where $\omega \boldsymbol{J} \boldsymbol{\psi}_{\text {Active }}=s \boldsymbol{\psi}_{\text {Active }} \equiv \boldsymbol{u}-R \boldsymbol{i}-L_{q} s \boldsymbol{i}$ must be substituted, and $\boldsymbol{K}=k_{1} \boldsymbol{I}-k_{2} \operatorname{sign}(\hat{\omega}) \boldsymbol{J}, k_{1}, k_{2}>0$.

SA2.3: Extended Kalman filter for the constant speed 4th-order nonlinear model (9] [15], or for model (9) with $s \omega=0$ being replaced by motion dynamics (2) [16].

SA2.4: As an alternative to SA2.3, transforming (9) into $d q-$ frame results in a 2nd-order open-loop current observer that is disturbed by position error $\tilde{\theta}_{d}=\theta_{d}-\hat{\theta}_{d}$ :

$$
\begin{aligned}
& L_{q} s \hat{i}_{d}=u_{d}-R i_{d}+\hat{\omega} L_{q} i_{q}+K_{\text {Active }} \hat{\omega} \sin \tilde{\theta}_{d} \\
& L_{q} s \hat{i}_{q}=u_{q}-R i_{q}-\hat{\omega} L_{q} i_{d}-K_{\text {Active }} \hat{\omega} \cos \tilde{\theta}_{d}
\end{aligned}
$$

for which the $\tilde{\theta}_{d} \approx 0$ assumption simplifies the unknown position error terms as $\sin \tilde{\theta}_{d}=\tilde{\theta}_{d}$ and $\cos \tilde{\theta}_{d}=1$.

SA3: Voltage model with voltage compensation using (6):

$$
\hat{\boldsymbol{\psi}}_{s}=\hat{\boldsymbol{\psi}}_{\text {Active }}+L_{q} \boldsymbol{i}=\int_{0}^{t}(\boldsymbol{u}-R \boldsymbol{i}+\hat{\boldsymbol{D}}) \mathrm{d} t
$$

where $\hat{D}$ is the stabilizing voltage yet to be designed.

\footnotetext{
${ }^{1}$ The term 'dynamic' means the correction $f$ has internal state, implying $f$ involves integral operation. Disturbance observer with dynamic correction is in the form of a state observer with an extended state (similar idea to ESO).
}

SA4: Flux compensation for VM based on DO using (8):

$$
\begin{aligned}
\frac{\mathrm{d}}{\mathrm{d} t} \hat{\boldsymbol{\psi}}_{s} & =\boldsymbol{f}_{1}\left(\hat{\boldsymbol{\psi}}_{s}-\hat{\hat{\boldsymbol{\psi}}}_{s}\right)+\hat{\omega} \boldsymbol{J}\left(\hat{\hat{\boldsymbol{\psi}}}_{s}-\hat{\boldsymbol{D}}_{\psi}\right) \\
\mathrm{d} \mathrm{d} t & \hat{\boldsymbol{D}}_{\psi}=\boldsymbol{f}_{2}\left(\hat{\boldsymbol{\psi}}_{s}-\hat{\hat{\boldsymbol{\psi}}}_{s}\right)
\end{aligned}
$$

where $\hat{\psi}_{s}$ is obtained by (19), and the estimated flux disturbance $\hat{\boldsymbol{D}}_{\psi}$ is used for building $\hat{\boldsymbol{D}}$ in $(19)$. The final flux estimate is $\hat{\boldsymbol{\psi}}_{s}-\hat{\boldsymbol{D}}_{\psi}$ rather than $\hat{\hat{\boldsymbol{\psi}}}_{s}$.

In summary, SA1 and SA4 are disturbance observers (DOs), and the difference is that SA1 assumes voltage disturbance in the current dynamics while SA4 assumes a flux disturbance as $\hat{\boldsymbol{\psi}}_{s}=\boldsymbol{\psi}_{s}+\boldsymbol{D}_{\psi}$. Note SA4 is an example of DO with dynamic correction $\hat{\boldsymbol{D}}_{\psi}$. SA2 is state observer, and its difference from DO is that state observer has a model for the unknown state $2^{2}$ SA2 and SA4 always rely on a speed estimate $\hat{\omega}$. SA3 is integrator, and its difference from SA4 is that SA3 relies solely on voltage compensation in the integrator input, while SA4 further utilizes flux compensation at the integrator output.

SA1-4 are the multi-input multi-output (MIMO) version of the story that links SA1-4 in Appendix A

- SA1 is the MIMO version of DO (39), (40) and (41).

- SA2 is the MIMO version of state observer (42) and (43).

- SA3 is the MIMO version of voltage compensation (44).

- SA4 is the MIMO version of flux compensation $\hat{D}_{\alpha \psi}$.

Remark 1: SA4 is a cascaded DO rather than a reducedorder observer. SA4 is also not a CAO because it does not implement speed adaptation law but instead uses $\hat{\omega}$ extracted from the prior flux estimate $\hat{\psi}_{s}$ [13].

6) Speed SA Designs: The model based $\omega_{r}$ or $\omega$ estimation can be achieved by the following generic SAs:

SA5: Direct calculation from $d q$-frame emf using the simplified steady state model of (10) or 11):

$$
\hat{\omega}=\hat{e}_{q, \mathrm{ss}} / K_{\text {Active }}, \quad \text { if } \hat{e}_{d, \mathrm{ss}}=0
$$

or direct calculation from position estimate by forward difference of $\hat{\omega}=\frac{\mathrm{d}}{\mathrm{d} t} \hat{\theta}_{d}$, or direct calculation from stator flux and stator emf $\boldsymbol{e}_{s}$ by: $\hat{\omega}\left(\hat{\boldsymbol{\psi}}_{s}^{\top} \hat{\boldsymbol{\psi}}_{s}\right)=-\left(\boldsymbol{J} \hat{\boldsymbol{\psi}}_{s}\right)^{\top} \boldsymbol{e}_{s}$.

SA6: Speed adaptation law driven by some output error $\varepsilon$ :

$$
\frac{\mathrm{d}}{\mathrm{d} t} \hat{\omega}=\text { Gain } \times \text { Regressor } \times \varepsilon
$$

SA7: Speed observer using (2) corrected by output error $\varepsilon$

$$
\begin{aligned}
\frac{\mathrm{d}}{\mathrm{d} t} \hat{\omega}_{r} & =n_{\mathrm{pp}} J_{s}^{-1}\left(T_{\mathrm{em}}-\hat{T}_{L}\right)+k \varepsilon \\
\text { or simply } \frac{\mathrm{d}}{\mathrm{d} t} \hat{\omega}_{r} & =\hat{a}+k \varepsilon
\end{aligned}
$$

where the dynamics of $\hat{T}_{L}$ and $\hat{a}$ are yet to be designed. To sum up, SA5 and SA6 are inertia-free, while SA7 often depends on inertia but provides an estimate of load torque; SA6 is often derived by Lyapunov analysis that requires constant $\omega$ assumption to ensure the aymptotical stability of output error $\varepsilon$. 23b is an inertia-free variant of 23a. A generalized form of SA7 is (46) in Appendix B. 


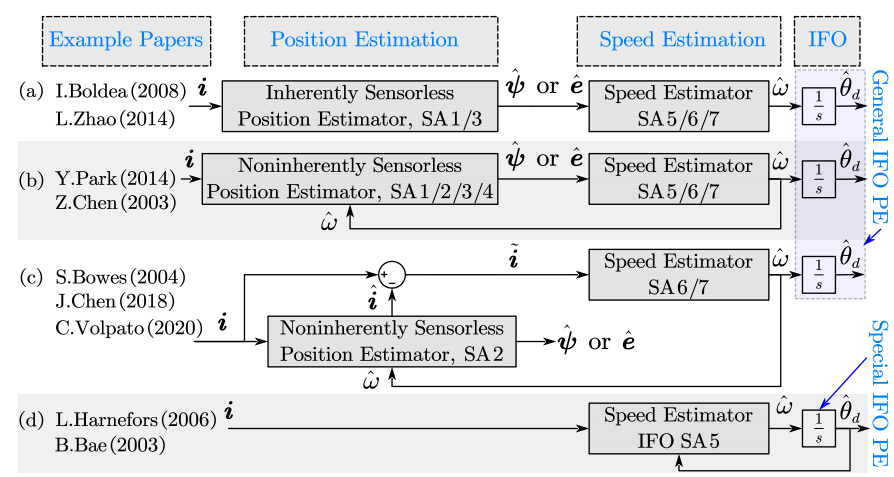

Fig. 1. Four complete sensorless algorithm schemes from example papers: (a) [1], [17], (b) [6], [13], (c) [18]-[20], (d) [3], [21].

7) Complete Schemes for Estimation of Position and Speed: Four typical sensorless schemes are presented in Fig. 1. Fig. 11a) shows that inherently sensorless position estimation (IS-PE) results in a cascaded framework. Fig. 1(b) and Fig. 1.c) reveal that non-inherently sensorless position estimation (non-IS-PE) results in an interconnected framework. Fig. 1.d) exemplifies that the position estimation can be skipped by introducing the indirect field orientation (IFO), i.e., to get position from integral of speed: $\hat{\theta}_{d}=\int \hat{\omega} \mathrm{d} t$.

The block diagram of a sensorless control system using SA3/4 and SA5/6 is shown in Fig. 2 In order to achieve the least parameter dependency, the speed is extracted from the stator flux, which is, however, reported in [22] to have much worse dynamic performance compared with the speed extracted from the active flux.

\section{InHERENTLy SENSORLESS Position Estimation} (IS-PE)

As shown in Fig. 11(a), in the framework of IS-PE, the output is the $\theta_{d}$-related state (i.e., flux or emf), the input is the measured current $i$, and the model is (6), i.e., 2nd order flux $\frac{\mathrm{d}}{\mathrm{d} t} \boldsymbol{\psi}_{s}$ and 2 nd order current $\frac{\mathrm{d}}{\mathrm{d} t} \boldsymbol{i}$ that correspond to the two algorithms, SA3 and SA1, respectively. This section reviews the IS versions of SA3 and SA1, and their associated issues and improvements.

\section{A. IS-SA3: Stabilized Voltage Model (VM) of Flux $\boldsymbol{\psi}_{s}$}

SA3 applies pure integration to the calculated emf, and the integration is stabilized by voltage compensation $\hat{D}$ or flux compensation $\hat{\boldsymbol{D}}_{\psi}$. When there is a drift $\boldsymbol{D}_{\psi}=\int_{0}^{t} \boldsymbol{D} \mathrm{d} t$ in the flux estimate, the resulting errors in position and speed estimation can be derived as in [23. Eqs. (19), (21)]. In order to build the stabilizing terms $\hat{D}$ or $\hat{D}_{\psi}$, several assumptions are resorted to, including:

(i) the constant $K_{\text {Active }}$ assumption [cf. (4)], so the active flux trajectory (i.e., the Lissajous curve) is circular;

(ii) the orthogonality between flux and emf:

$$
\boldsymbol{e}_{\text {Active }}=\omega \boldsymbol{J} \psi_{\text {Active }}[\mathrm{cf} \text {. 7a ] }
$$

(iii) and the orthogonality between $\alpha$-axis and $\beta$-axis emfs: $\dot{e}_{\text {Active }}=\omega \boldsymbol{J} e_{\text {Active }}[\mathrm{cf} .(7 \mathrm{~b}]$ ].

Both assumption (ii) and (iii) are built upon assumption (i), and assumption (i) leads to assumption (ii) and (iii) if $\dot{\omega}=0$. Several tools are proposed and can be combined to build $\hat{\psi}_{s}$.

${ }^{2} \mathrm{SA} 2.1$ (emf observer) is a dynamic DO assuming sinusoidal disturbance.

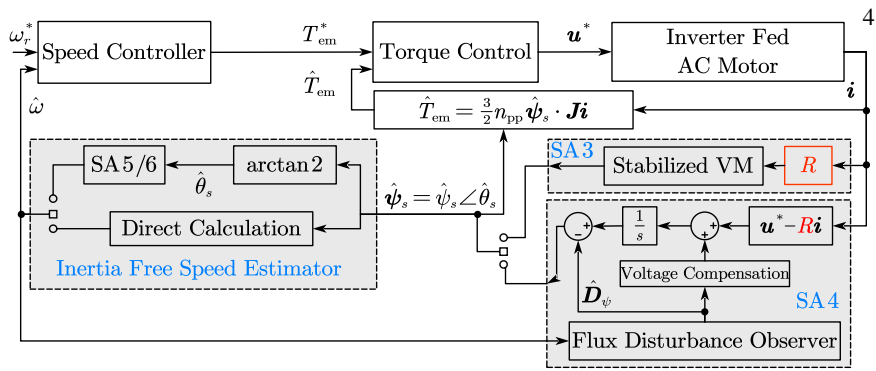

Fig. 2. Block diagram of a least-parameter-dependency sensorless scheme. Inherently sensorless SA3 is shown, while the SA4 needs a speed estimate.

1) Amplitude Limiter: The pure integrator output $\frac{\boldsymbol{u}-R \boldsymbol{i}}{s}$ will diverge to infinity. To avoid this, one can add an amplitude limiter to constrain the amplitude of the integrator output within $K_{\text {Active }}$ by means of flux compensation [24, Fig. 2], or voltage compensation [25].

2) Origin of Flux Vector Trajectory: Another corollary of the constant $K_{\text {Active }}$ assumption is that an accurate $\alpha$-axis flux estimate $\hat{\psi}_{\alpha s}$ should be a sinusoidal signal whose maximum and minimum add up to null. In other words, the origin of the flux estimate over one electrical cycle, i.e.,

$$
\hat{\boldsymbol{D}}_{\psi}=\frac{1}{2}\left[\begin{array}{c}
\max \left(\hat{\psi}_{\alpha s}\right)+\min \left(\hat{\psi}_{\alpha s}\right) \\
\max \left(\hat{\psi}_{\beta s}\right)+\min \left(\hat{\psi}_{\beta s}\right)
\end{array}\right]
$$

should be $\mathbf{0}$. If $\hat{\boldsymbol{D}}_{\psi}$ in 24 is not null, one can directly use it to produce a final flux estimate as $\hat{\psi}_{s}-\hat{D}_{\psi}[23]$, or one can use it to construct a voltage compensation as $\hat{\boldsymbol{D}}=\operatorname{LPF}(s) \hat{\boldsymbol{D}}_{\psi}$ [25]. In fact, the voltage compensation error $\boldsymbol{D}-\hat{\boldsymbol{D}}$ can be exactly calculated from $\hat{\boldsymbol{D}}_{\psi}$ by utilizing time information [26].

Remark 2: As discussed in [22, Sec. III], it is better to use active flux to calculate $\hat{\boldsymbol{D}}_{\psi}$ in (24), because stator flux components are not sinusoidal with sudden change in current. For FOC drive, the active flux is obtained from (4), while for DTC drive, the angle between active flux and stator flux can be found by looking up the torque angle [22].

3) Amplitude Correction: Amplitude limiter does not work when the estimated flux amplitude is less than $K_{\text {Active }}$ [2], so it is natural to replace the limiter with an amplitude correction as follows [2], [27]- 35$]^{3}$

$\hat{\boldsymbol{D}}=\mathrm{PI}(s) \boldsymbol{P}\left(\hat{\theta}_{d}\right)\left[\begin{array}{l}\varepsilon \\ 0\end{array}\right]=\mathrm{PI}(s) \frac{\varepsilon \hat{\boldsymbol{\psi}}_{\text {Active }}}{\left\|\hat{\boldsymbol{\psi}}_{\text {Active }}\right\|}, \mathrm{PI}(s) \triangleq k_{1}+\frac{k_{2}}{s}$

where $\varepsilon=K_{\text {Active }}-\left\|\hat{\boldsymbol{\psi}}_{\text {Active }}\right\|$ is the amplitude mismatch. 26 can be interpreted as transforming the $d$-axis mismatch $\varepsilon$ back to $\alpha \beta$ frame. SA3 plus (26) describes the classical hybrid flux estimator that outputs the sum of high-pass filtered voltage model estimate and low-pass filtered current model estimate, and leads to the classical interpretation that voltage model is used for high speeds and current model is used for low

${ }^{3}$ The flux amplitude mismatch $\varepsilon$ from 26 has an equivalent current error form 25a, if a current estimate $\hat{\boldsymbol{i}}$ is introduced as 25b:

$$
\begin{aligned}
\boldsymbol{i}-\hat{\boldsymbol{i}} & =L_{q}^{-1} \hat{\boldsymbol{\psi}}_{\text {Active }}\left(\frac{K_{\text {Active }}}{\left\|\hat{\boldsymbol{\psi}}_{\text {Active }}\right\|}-1\right)=L_{q}^{-1} \frac{\varepsilon \hat{\boldsymbol{\psi}}_{\text {Active }}}{\left\|\hat{\boldsymbol{\psi}}_{\text {Active }}\right\|} \\
\hat{\boldsymbol{i}} & =L_{q}^{-1}\left(\hat{\boldsymbol{\psi}}_{s}-\frac{\hat{\boldsymbol{\psi}}_{\text {Active }}}{\left\|\hat{\boldsymbol{\psi}}_{\text {Active }}\right\|} K_{\text {Active }}\right)
\end{aligned}
$$

which is used, e.g., in [28], to build a sliding mode variant of 26. 


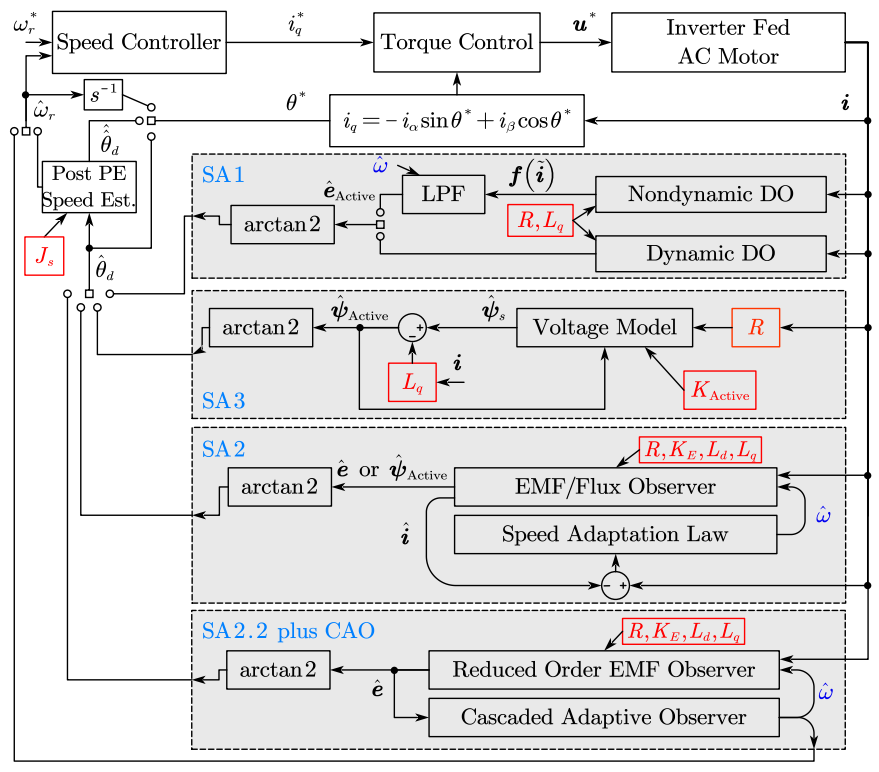

Fig. 3. Block diagram of the disturbance observer.

speeds [2], [27], [34]. Discussions for selection of $k_{1}, k_{2}$ is documented in [2], [27], and it is suggested in [2] to set $k_{2}$ to zero for slow speed reversal. Coincidentally, a contribution from the control community also suggests to not implement the $k_{2}$ integral term, but in a slightly different form from 26 as follows to facilitate the stability analysis [36], [37]

$$
\hat{\boldsymbol{D}}=k_{1} \hat{\boldsymbol{\psi}}_{\text {Active }}\left(K_{\text {Active }}+\left\|\hat{\boldsymbol{\psi}}_{\text {Active }}\right\|\right) \varepsilon
$$

In induction motor context, instead of rendering a constant $K_{\text {Active }}$ assumption, an equivalent statement is to impose the correction in terms of flux command [38], [39]. The difference is that the angle of the flux command can be determined by an IFO integrator, i.e., using a different angle for $\boldsymbol{P}\left(\frac{1}{s} \hat{\omega}\right)$ in [26) [38], instead of directly using the angle of flux estimate as in [39]. Similarly, the flux command is used in replace of $K_{\text {Active }}$ parameter for synchronous reluctance motor [40].

4) Compensation by Orthogonality: Another indicator of divergence of flux estimation is the violation of orthogonality condition that can be checked by calculating the dot product $\boldsymbol{e}_{s} \cdot \hat{\boldsymbol{\psi}}_{s}$ with the emf due to stator field $\boldsymbol{e}_{s} \triangleq \boldsymbol{u}-R \boldsymbol{i}$. Based on this dot product, one can implement flux compensation as in [24, Fig. 3].

\section{B. IS-SA1: Disturbance Observer (DO) for EMF $\boldsymbol{e}_{\text {Active }}$}

The working principle of SA1 is to use the correction term $\boldsymbol{f}(\tilde{\boldsymbol{i}})$ to force $\boldsymbol{i}$ to track $\boldsymbol{i}$. To make this happen, the norm of $\boldsymbol{f}(\tilde{\boldsymbol{i}})$ should be larger than the disturbance $\left\|\boldsymbol{e}_{\text {Active }}\right\|$. As a result, $\boldsymbol{f}(\tilde{\boldsymbol{i}})$ itself serves as an estimate of $\boldsymbol{e}_{\text {Active. }}$. However, $\left\|e_{\text {Active }}\right\|$ is proportional to $\omega$, and to assure a wide operating speed range, large correction gain is needed for non-dynamic $f$, in which case the speed-dependency of the performance of the IS observer is inevitable. A simple fix is to use a variable correction as a function of $\hat{\omega}$, which, however, will make SA1 lose its IS property, and will result in an interconnected nonIS framework as shown in Fig. 1 (b). This dilemma can be resolved by implementing $f$ as dynamic correction.
1) Sliding Mode Disturbance Observer (SMDO): SMDO is a nonlinear DO, and originally implements correction $f$ in SA1 as ${ }^{4} \boldsymbol{f}=k \operatorname{sign}(\boldsymbol{S})$ that consists of three parts, i.e., SM surface $\boldsymbol{S}$, SM gain $k$, and SM control law $\operatorname{sign}(\cdot)$. Improvements on those three components are now reviewed.

The large SM gain requirement leads to chattering in the emf estimate $f$. To mitigate the chattering issues, it is proposed to use "milder" SM control law than the discontinuous correction $\operatorname{sign}(\cdot)$, such as saturation function [41], and sigmoid function [42]-[44]. Additionally, the $f$ in [41], [44] is a linear combination of SM correction and proportional correction.

By using large but constant SM gain, SMDO is an IS$\mathrm{PE}$, but in order to reduce excessive noises in the estimated disturbance emf $\boldsymbol{f}$, an additional LPF is typically applied to $f$, before $\hat{\theta}_{d}$ can be extracted. The phase delay caused by the LPF should be compensated for different speeds [45]-[47]. Given a constant SM gain, it is suggested that the pole of the LPF should rely on $\hat{\omega}[41]$, leading to a non-IS-PE design, as shown in Fig. 3 Additionally, it is proposed to use smaller SM gain and execute the SMDO at a frequency that is 3 times as high as the PWM frequency [45], [48].

To achieve an IS-SMDO, it is recommended to implement $f$ as a dynamic correction that puts signum inside an integral. This integral introduces an additional state, resulting in a second-order SMDO, and the second state can be interpreted as an estimate of the emf appearing in the current dynamics. For example, the super-twisting algorithm can be used to estimate the emf [17], [49], [50], and the resulting continuous $\alpha$-axis correction is $f_{\alpha}=k_{1}\left|i_{\alpha}\right|^{\frac{1}{2}} \operatorname{sign}\left(\tilde{i}_{\alpha}\right)+k_{2} \int \operatorname{sign}\left(\tilde{i}_{\alpha}\right) \mathrm{d} t$, where the integral term serves as a continuous estimate of the emf. As a comparison, the second-order SMDO in [51] uses discontinuous $\alpha$-axis correction as $f_{\alpha}=k_{1} \operatorname{sign}\left(\tilde{i}_{\alpha}\right)+$ $k_{2} \int \operatorname{sign}\left(\tilde{i}_{\alpha}\right) \mathrm{d} t$. Note the continuity of $f_{\alpha}$ is decided by the $k_{1}$ term, and also note applying variable gain $k_{1}\left|\tilde{i}_{\alpha}\right|^{\frac{1}{2}}$ to $\operatorname{sign}\left(\tilde{i}_{\alpha}\right)$ does not eliminate chattering because the derivative of $\left|\tilde{i}_{\alpha}\right|^{\frac{1}{2}}$ is infinite when $\tilde{i}_{\alpha}=0$. The chattering is reduced because of using smaller $k_{1}$ value and nonzero $k_{2}$.

So far, all SMDOs reviewed above use current error $\tilde{i}$ as the SM surface $\boldsymbol{S}$-the argument of $\operatorname{sign}(\cdot)$. Improvement is expected by further designing SM surfaces. For example, SM surface involving current error integral $\int \tilde{\boldsymbol{i}} \mathrm{d} t$ (see, e.g., [52]) preserves observer robustness during reaching phase [53], [54]. SM surfaces involving current error derivative $\tilde{\boldsymbol{i}}$ promise faster observer convergence (i.e., "convergence in finite time"), including the fast terminal SM manifold [55] and the non-singular terminal SM manifold [46]. Note the current derivative needed in the manifold can be reconstructed using super-twisting algorithm [46].

Finally, the SM gain $k$ can be designed to be a function of $S$ [52], which is also known as the reaching law design in SM control theory.

2) Linear Disturbance Observer: By modeling emf as dc disturbance such that $\frac{\mathrm{d}}{\mathrm{d} t} \boldsymbol{e}_{\text {Active }}=\mathbf{0}$, Tomita et al. [56] propose to design the correction term as $\boldsymbol{f} \propto(\dot{\boldsymbol{i}}-\dot{\hat{\boldsymbol{i}}})$ for SA1, where the $\hat{\omega}$-dependent pole placement is mandatory, and is derived by analyzing the $H_{\infty}$ norm of transfer function from the

\footnotetext{
${ }^{4}$ Vector version of signum function is: $\operatorname{sign}(\boldsymbol{S})=\left[\operatorname{sign}\left(S_{\alpha}\right), \operatorname{sign}\left(S_{\beta}\right)\right]^{\top}$.
} 
unmodelled dynamics to the emf error. In [57], proportional correction $\boldsymbol{f} \propto \tilde{\boldsymbol{i}}$ is implemented. In [58], proportional-integral (PI) correction $\boldsymbol{f}=\mathrm{PI}(s) \tilde{\boldsymbol{i}}$ is used, resulting in a dynamic correction. The linear DO is deemed to be poorly damped if constant correction gain is used [59]. Frequency domain formulation of the DO with PI correction is proposed in [60], which is further generalized for salient PM motor in [61].

The constant emf disturbance assumption $\frac{\mathrm{d}}{\mathrm{d} t} e_{\text {Active }}=\mathbf{0}$ is apparently not reasonable [cf. (7b)]. Intuitively, emf in $d q$ frame can be modelled as dc disturbance, but transforming into $d q$-frame leads to non-IS-PE, which is discussed later in Sec. III-B2,

Remark 3: Nonlinear second-order SMDO with dynamic correction can track ac disturbance, while linear DO with PI correction cannot, as is discussed in Appendix A

\section{Magnetic Asymmetry (Saliency) based IS-PE}

There are magnetic asymmetry based SAs that can only be applied to certain types of ac motors. Magnetic asymmetry includes rotor slotting and rotor saliency. The former can be exploited for speed detection (see Sec. $\mathrm{V}-\mathrm{C}$ ) and the latter is utilized for IS-PE. For saliency due to main-flux saturation or machine structure, the inductance is a function of rotor position, and based on this fact, various invasive methods that involve excitation of high frequency voltage or carrier frequency voltage, are proposed. The readers are referred to [62], [63] for a dedicated review. It is worth mentioning that non-invasive saliency based $\mathrm{PE}$ is also possible, see e.g., [64] for a non-invasive detection of position from the switching function slopes in SM motor control. There is also a trend trying to extending the near zero-frequency performance of model based SAs by combining with saliency based PE [29], [31]-[33], [65]-[73].

The performance of the saliency based PE is influenced by the saturation induced magnetic cross-coupling, making the inset type of the salient PM motors more suited with higher load [74], and therefore there is also research trying to take self-sensing capability into consideration for motor design [74]-[76].

\section{NON-INHERENTLy SENSORLESS Position ESTIMATION (NON-IS-PE)}

As shown in Fig. 1.b) and 1.c), in the framework of nonIS-PE, the output is the $\theta_{d}$-related state (i.e., flux or emf), the input is current $i$ and speed $\hat{\omega}$, and the model is (7), (8), (10), (11) or (12). SA1 and SA3 have their non-IS variants, while SA2 and SA4 are always non-IS. This section will review non-IS-PE as two categories. The first category uses speed as a parameter in the model, while the other uses speed only for tuning estimator coefficients.

\section{A. Non-IS SA2/4 Due to Speed being Part of $\alpha \beta$-Frame Model}

Unlike SA1 and SA3, the unknown state, i.e., emf or active flux, is modelled as internal state in SA2 and SA4 such that the speed parameter $\omega$ appears, and $\omega$ is always replaced with a speed estimate $\hat{\omega}$, meaning that this type of non-IS-PE is disturbed by speed error, as shown in Fig. 3 SA2 is state observer for emf or flux, while SA4 is a reduced-order flux observer with flux disturbance estimation.

The key difference between full-order state observer and reduced-order state observer lies in how they treat speed error. SA2 in its full-order form reconstructs a current estimate $\hat{\boldsymbol{i}}$, and calculate the output error $\tilde{\boldsymbol{i}}$ to tune the speed estimate $\hat{\omega}$ using SA6. This requires that $\tilde{i}$ is sensitive to speed error $5^{5}$ On the other hand, since current $i$ is measured, there is no need to reconstruct $\hat{\boldsymbol{i}}$, and by assuming a speed signal $\hat{\omega}$ is available, the unknown state can be reconstructed by the reduced-order variants of SA2. This needs the state estimate to exhibit robustness against speed error via careful observer pole placement [6], [13].

1) EMF Observer (SA2.1): EMF observer can be implemented in its full-order form [20], [61], [70], [77]-[81] or in its reduced-order form [6]. In [70], [77], [80], [81], SM corrections are implemented. Time-varying gain that depends on SM surface is designed in [80] to reduce chattering, and SM emf observer is found to be easier to tune as compared with the extended Kalman filter for emf [80]. Proportional correction is used in [20] and linear system analysis is conducted to tune the observer. The $d q$-frame or more precisely $\gamma \delta$-frame implementation of the emf observer can be found in [78], where included is an interesting study that analyzes the consequences of using constant speed assumption in emf observer. In [61], the influence of dc offset on emf estimation is analyzed. In [79], observer steady-state errors are analyzed considering current/votlage error, parameter uncertainty and filtering.

As for the reduced-order variant of emf observer, the robustness against speed error can be designed through $H_{\infty}$ norm based pole placement [6].

2) Flux Observer (SA2.2): Flux observer can be implemented in its full-order form [9], [10], [78], [82], or in its reduced-order form [14]. In [78], the flux observer is implemented in $\gamma \delta$-frame, and the speed difference between $d q$-frame and $\gamma \delta$-frame that will result during speed transients is obtained from a cascaded speed observer. In [9], the flux observer is analyzed by Lyapunov stability theory through finding the positive-definite matrix for the Kalman-Yakubovich lemma. In [82], [83], SM state observer is proposed, and pole placement for robustness improvement is detailed in [83].

In [14], reduced-order flux observer (17) is analyzed in the misaligned $\gamma \delta$-frame, and is described by a rotatory differential operator: $\boldsymbol{P}(\theta) s \boldsymbol{P}^{-1}(\theta)=s \boldsymbol{I}+\dot{\theta} \boldsymbol{J}$ and the stability analysis of the flux observer holds only if speed is known.

3) Linearized Position Observation by EKF (SA2.3): EKF can be applied to the nonlinear model (9) [15], [84]. The fourth-order extended state model (9) assumes both constant active flux amplitude and constant speed. It is also possible to use stator flux $\psi_{s}$ as state instead of $i$ [84], where the flux output error is equivalent to the current error that was revealed

\footnotetext{
${ }^{5}$ Large corrections in the current observer dynamics will reduce the current error's sensitivity to speed error. In extreme case, the speed error is forced to be zero (e.g., trapped in SM surface), and therefore there is no way to extract speed signal from current error. This fact dis-encourages the idea of speedadaptive SM state observer, but motivates the idea of cascaded speed-adaptive observer.
} 
in 25a. In addition, the constant speed model $\frac{\mathrm{d}}{\mathrm{d} t} \omega=0$ can be replaced with the motion dynamics (2) and the resulting EKF implementation can be found in [16].

4) Current Observer in dq-frame (SA2.4): The $d$-axis current observer 18a can be understood as an adaptive observer with constant position error parameter $\tilde{\theta}_{d}$, provided that $\hat{\omega}$ is available and accurate-which is a typical assumption in nonIS-PE design. The observer can be implemented as an openloop one [85] [86, Sec. 9.2.2] or a closed-loop one [87].

Since the $d$-axis current error contains the information of position error $\tilde{\theta}_{d}$, PLL can be used to form an estimate of position [87].

Remark 4: Both SA2.4 and SA1 use 2nd-order $\frac{\mathrm{d}}{\mathrm{d} t} \boldsymbol{i}$ dynamics. The difference is that for SA1, a correction is necessary, while SA2.4 can be implemented as open-loop observer. $\triangle$

5) Frequency-Adaptive System (SA4): The idea of SA4 is to remove the flux disturbance in the sinusoidal flux estimate prior obtained from SA3. Therefore, SA4 is called frequencyadaptive DO in literature [13], [34], and is in fact a cascaded flux observer using (8). The robustness of the cascaded flux estimate $\hat{\hat{\psi}}_{s}$ against speed error is analyzed in [13, Fig. 2]. Note the observer tuning or pole placement in [13] is also dependent on $\hat{\omega}$. Alternatively, we can understand the overall system of voltage model estimator (SA3) and its DO (SA4) as a "single tune integrator" [88], [89], whose performance relies on the speed estimate. SA4 is typical non-IS-PE with speed dependency in both model and tuning, as shown in Fig. 2

The readers are referred to [59, Table 4] for a review of the frequency adaptive observers for eliminating emf harmonics.

\section{B. Non-IS Variants of $S A 1 / 3$}

Even though the original implementation of SA1 and SA3 is IS, it is possible to introduce speed-dependency by i) modeling a different disturbance emf for SA1, ii) using a speed-dependent orthogonal condition, or iii) implementing SA1 and SA3 in $d q$-frame. Those non-IS variants are less recommended, though one benefit is that the ac emf disturbance becomes dc disturbance in $d q$-frame.

1) Speed-Dependent Disturbance Model for SA1: In (13), the disturbance is the emf due to active flux. However, one can also implement SA1 (e.g., [41]) using the extended emf model in (12), resulting in a non-IS SMDO as is done in [68].

2) dq-Frame Variant of SA1: In Sec. II-B2, the linear DO method assumes the dynamics of the ac emf to be zero. This assumption becomes more reasonable if one transforms (13) into $d q$-frame, such that $d q$-frame emf is modelled as dc disturbance and the correction $\boldsymbol{f}$ becomes $\boldsymbol{P} \boldsymbol{f}$. In [71], [90], [91], $\boldsymbol{P} \boldsymbol{f}$ is implemented as a PI law, resulting in a dynamic correction. In [92], a classical DO (that uses LPF) is proposed to estimate the extended emf $\boldsymbol{e}$ in $d q$-frame In [69], [93], SMDO is proposed in $d q$ frame. In [69], the $d q$-frame correction $\boldsymbol{P} \boldsymbol{f}$ is implemented as a combination of proportional correction and SM correction. In [93], a speeddependent SM surface that consists of current error and its integral is selected, and the correction $\boldsymbol{P} \boldsymbol{f}$ is a dynamic one.

\footnotetext{
${ }^{6}$ The analysis in [92] is in $\gamma \delta$-frame but the implementation is in $d q$-frame. For an example of $\gamma \delta$-frame observer implementation, see [78 Eqs. (17)].
}

3) Speed-Dependent Orthogonal Condition for SA3: Recall that the dot product scalar orthogonality condition $\boldsymbol{e}_{s} \cdot \boldsymbol{J} \hat{\boldsymbol{\psi}}_{s}=$ 0 does not involve speed signal, but one can derive an speeddependent vector orthogonality condition as $\boldsymbol{e}_{s}-\hat{\omega} \boldsymbol{J} \hat{\boldsymbol{\psi}}_{s}=\mathbf{0}$, based on the assumption (ii) from Sec. II-A Voltage compensation $\hat{\boldsymbol{D}}$ based on $\boldsymbol{e}_{s}-\hat{\boldsymbol{\omega}} \boldsymbol{J} \hat{\boldsymbol{\psi}}_{s}=\mathbf{0}$ is proposed in [94], [95].

4) $d q$-Frame Variant of SA3: Voltage model (19) is IS because it is in $\alpha \beta$ frame. Transforming (19) into $d q$ frame makes the flux estimator coupled with speed estimation, resulting in a non-IS-PE. The current error in 25 that is based on the assumption (i) from Sec. II-A can be used to build a speedadaptive voltage model in $d q$-frame [67], [73].

\section{Speed Only being Used for Tuning}

Since the SA2/4 have speed in the model, it is natural to also use speed for tuning (e.g., pole allocation). On the other hand, IS-SA $1 / 3$ have the potential to be implemented being free of speed, but the IS property is lost if speed is used for tuning in SA1/3.

1) Non-IS Tuning for SAl: We have already addressed in Sec. II-B that speed-dependent tuning is often adopted for SA1, e.g., the linear DO whose pole placement is dependent on $\hat{\omega}$, and the first-order SMDO with non-dynamic correction whose switching gain or ensuing LPF is dependent on $\hat{\omega}$. There are also examples of speed-dependent tuning for second-order SMDO with dynamic correction, see e.g., [50, (10)]. In other words, some practical implementation of SA1 requires speeddependent tuning, resulting in non-IS-PE.

This section will now focus on the speed-dependent tuning that makes SA3 non-IS.

2) Non-IS Tuning for SA3: In order to stabilize the pure integration in SA3, a high pass filter (HPF) can be added to the output of the voltage model [96], which is equivalent to replace the integrator with an LPF as follows:

$$
\hat{\boldsymbol{\psi}}_{s}=\frac{\omega_{\mathrm{LPF}}}{s+\omega_{\mathrm{LPF}}} \boldsymbol{e}_{s}, \quad \boldsymbol{e}_{s} \triangleq \boldsymbol{u}-R \boldsymbol{i}
$$

which is IS if a fixed $\omega_{\mathrm{LPF}}$ is used. In fact, it is reported that placing the LPF pole, $-\omega_{\mathrm{LPF}}$, to be close to zero is sufficient for zero speed ${ }^{7}$ operation of induction motor [97], but it is often recommended to adopt the non-IS tuning $\omega_{\mathrm{LPF}}=k|\hat{\omega}|$ to adjust observer damping with respect to speed [5], [98]. In order to compensate the gain and phase shift introduced by the LPF, a compensation term is introduced as follows [5], [98]-[102]:

$$
\hat{\boldsymbol{\psi}}_{s}=\underbrace{\frac{1}{s+k|\hat{\omega}|} \boldsymbol{e}_{s}-\boldsymbol{J} \frac{k \operatorname{sign}(\hat{\omega})}{s+k|\hat{\omega}|} \boldsymbol{e}_{s}}_{\text {Two low pass filtered signals add up }}=\underbrace{\frac{[\boldsymbol{I}-k \boldsymbol{J} \operatorname{sign}(\hat{\omega})] \boldsymbol{e}_{s}}{s+k|\hat{\omega}|}}_{\text {There is only one filter [100] }}
$$

which is called statically compensated voltage model (SCVM) [5], [21] because the compensation is only exact at steady state when $\omega$ is constant. It is suggested in [100] to apply the static compensation to the stator emf $e_{s}$ first before going through the LPF, as indicated by the text under the equations in 29. See [5], [100], [101] for different advice for choices of $k$ in

\footnotetext{
${ }^{7}$ Zero speed $\omega_{r}=0$ does not mean $\omega=0$ for induction motor with load
} 
[29]. In [103], three speed-dependent cascaded LPFs are used to recover the frequency response of integrator.

Note that the presence of skew-symmetric matrix $\boldsymbol{J}$ in 29) means, e.g., $\beta$-axis emf is used for compensating $\alpha$-axis dynamics, and this practice implicitly assumes an orthogonality relation between $\alpha$-axis and $\beta$-axis, i.e., $\int_{t}^{t+\frac{2 \pi}{\omega}} e_{\alpha s} e_{\beta s} \mathrm{~d} t=08^{8}$ which is the assumption (iii) from Sec. II-A However, if some signal phase shift network is introduced, the compensation can be accomplished within the same axis, and therefore even elliptical trajectory of stator flux vector can be tracked [104].

\section{Post-Position Estimation (PE) Speed Estimation}

Post-PE speed estimation extracts speed signal from an assumedly-accurate flux/emf estimate or an erroneous current estimate $\hat{i}$ that is disturbed by $\tilde{\omega}$, as shown in Fig. 1 a), 1 (b), and 1 (c). For post-PE speed estimation, the output is $\hat{\omega}$; the input is $\hat{\theta}_{d}$-related states or current error $\tilde{i}$; and the model is constant speed model $\frac{\mathrm{d}}{\mathrm{d} t} \omega=0$, steady state model of (10), or motion dynamics (2). The generic algorithms are SA5-7.

\section{A. Post-PE-SA5: Direct Calculation}

1) Direct Calculation from Position: Speed estimate can be calculated by the forward difference of the flux angle $\hat{\theta}_{d}$ [10], [23], and an additional LPF is embedded to reduce the amplified noise in [23].

2) Direct Calculation from Orthogonality between Flux and $E M F$ : Acknowledging the fact that speed signal exists in the dynamics of the derivative of stator flux, it can then be calculated as $\hat{\omega}\left(\hat{\boldsymbol{\psi}}_{s}^{\top} \hat{\boldsymbol{\psi}}_{s}\right)=-\left(\boldsymbol{J} \hat{\boldsymbol{\psi}}_{s}\right)^{\top} s \hat{\boldsymbol{\psi}}_{s}$, where the derivative of flux can be substituted with the calculated stator emf as $\boldsymbol{e}_{s}=\boldsymbol{u}-R \boldsymbol{i}$ [98], [99], [105], the SMDO emf estimate [55], [106], [107], or the forward difference of flux [108]. In [109],

3) Direct Calculation from Emf: Speed is simply the emf amplitude divided by the flux amplitude [46], [49].

\section{B. SA6: Model Reference Adaptive System (MRAS)}

An adaptive observer is established based on the fact that the output error $\varepsilon$ is measurable and can be used to drive the speed adaptation law (22). Therefore, for sensorless ac motors, the output error $\varepsilon$ should always be the current error $\tilde{\boldsymbol{i}}$, and the adaptive observer is of full-order. From the perspective of model reference adaptive system (MRAS), the actual motor is the reference model, and the full-order adaptive observer is the adjustable model.

Now consider an MRAS, where the reference model is an IS-PE, and then one can implement a reduced-order adaptive observer as the adjustable model. Such adjustable model is called cascaded adaptive observer $(\mathrm{CAO})$ in this paper.

Full-order adaptive observer has an interconnected structure between PE and speed estimation, while the CAO is designed to be a cascaded speed estimation sub-system that comes after the PE sub-system. However, if the reference model is a nonIS-PE, then the resulting MRAS (of the non-IS-PE and CAO) is interconnected.

\footnotetext{
${ }^{8}$ If $K_{\text {Active }}$ and $\omega$ are constant, then $\int_{t}^{t+\frac{2 \pi}{\omega}} e_{\alpha, \text { Active }} e_{\beta, \text { Active }} \mathrm{d} t=0$ is valid, and it is also true for stator emf if $d$ - and $q$-axis currents are constant.
}

1) CAO Based on Prior $\hat{\theta}_{d}$-related States: CAO assumes that an accurate estimate of the unknown states, e.g., position $\hat{\theta}_{d}$, emf $\hat{\boldsymbol{e}}$ or flux $\hat{\boldsymbol{\psi}}_{s}$, is available, and an speed-adaptive reduced-order observer based on output error $\varepsilon=\hat{\theta}_{d}-\hat{\hat{\theta}}_{d}$, $\varepsilon=\hat{\boldsymbol{e}}-\hat{\hat{\boldsymbol{e}}}$ or $\varepsilon=\hat{\boldsymbol{\psi}}_{s}-\hat{\hat{\boldsymbol{\psi}}}_{s}$ is further reconstructed for observing the "estimate of unknown states" as an effort to extract the hidden speed information by a speed update law (22).

EMF-type CAO, as shown in Fig. 3, is implemented in [6], [43], [44], [52], [54], [57], [61]. Flux-type CAO can be found in [82], but what is much more often to see is to use the angle of the flux estimate to build a position-type CAO-which is also known as phase-locked loop (PLL).

PLL is widely used for post-PE speed estimation. During formulation of PLL, various types of position error signals can be exploited, such as the $q$-axis voltage [101], the angle of $\gamma \delta$-frame extended emf [71], $d$-axis current error from (18a) [87], and the forward difference of high frequency components of $\alpha \beta$-frame current [110]. PLL for induction motors would need to add an additional slip relation [5]. Speed error during speed transients is inevitable because typical PLL is 2nd-order system that assumes constant speed [111], which is a type2 system [13]. The transfer function from actual position to estimated position can be found in [92, Eq. (18)] and [71 Eq. (39)] The speed error from PLL during speed dynamics is analyzed in [58]. In [29], an additional PI term driven by torque error is further added to the PLL based speed estimate. PLL can be generalized for higher order to track time-varying speed [14, Eq. (24)], and see also [35] and [92, Eq. (22)] for an application of type-3 PLL for tracking ramp speed signal.

Generally speaking, when designing for post-PE speed estimation, a position signal $\hat{\theta}_{d}$ is assumed to be available and accurate, meaning that no correction for $\hat{\theta}_{d}$ is done during post-PE speed estimation stage. However, the reality is that non-IS observer is disturbed by speed error and that the emf estimate is probably obtained from an LPF, thus lagged response of $\hat{\theta}_{d}$ with respect to $\theta_{d}$ is expected. A remedy is proposed in [60] to compensate the delay in the estimated emf during the post-PE speed estimation stage using PLL.

2) Speed Adaptation Law Using Prior Current Error $\varepsilon=$ $\tilde{i}$ : The speed adaptation law (22) is driven by the estimated current error $\tilde{\boldsymbol{i}}$. The regressor depends on how speed appears in the adopted model, and typical choices of regressors are stator flux [69] and extended emf [20]. Particularly, in (18b], the regressor is $K_{\text {Active }}$ [87]. Speed adaptation treats the speed as a constant parameter, but one can design an inertia-dependent speed-adaptation law that includes an additional torque term [87], [108].

\section{SA7: Speed Observer}

1) Observer with Constant Load Torque Assumption (23a): Speed observer (SA7) uses the motion dynamics (2) to extract speed information from the prior position estimate, resulting in a 3rd-order state observer for position, speed, and load torque [40], [78], [90], [110] [112, Fig. 9]. SA7 often assumes a constant load torque, and has various names, such as extended Luenberger observer (ELO) [113, Sec. 4.5.3.5] or extended state observer (ESO) [47], [114]-[116]. Particularly, nonlinear 
correction is used in [115], [116]. See (45) in Appendix B for a discussion of those speed observer variants.

Alternatively, one can also design a 3rd-order state observer using $q$-axis current, speed and load torque as states, which can be understood as a reduced-order implementation of the original natural speed observer [18] for either PM motors [2] or induction motors [105], and can also be understood as an ELO implementation of the $q$-axis current observer [18b] [87]. The difference is that the natural speed observer uses motor active power error as the scalar output error $\varepsilon$, which, however, makes observer tuning to be dependent on $q$-axis voltage [2].

2) Inertia-Free Variant of Speed Observer (23b): In [70], [77], an extended Kalman filter type speed observer is proposed for a 3rd-order system of position, speed and acceleration, without needing inertia parameter $J_{s}$.

\section{Speed Estimation For Indirect Field ORIENTATION (IFO)}

If the angle used in Park transformation $\boldsymbol{P}$ is an integral of a speed estimate, the torque control is said to be dynamic and based on IFO. In this sense, IFO is a special kind of non-IS-PE with the simplest dynamics: $\hat{\theta}_{d}=\frac{1}{s} \hat{\omega}$. The interesting idea is that now we can construct the speed estimation based on the IFO position estimate $\frac{1}{s} \hat{\omega}$, rather than assuming some accurate position estimate is available, which is a completely different design philosophy from post-PE speed estimation because of this special input, as shown in Fig. 11(d).

\section{A. General IFO-PE}

Generally speaking, we can add an additional IFO integrator to the output of any post-PE speed estimation, to achieve general IFO-PE, as shown in Fig. 1 (a), 1 (b), and 1. (c). The IFO integrator provides an additional position estimate as $\frac{1}{s} \hat{\omega}$ that can be used in e.g., SA3 [38], as is discussed in Sec. II-A3 to design voltage compensation $\hat{D}$ for induction motors.

\section{B. IFO-SA5: Closed-loop Direct Calculation from EMF}

This sub-section reviews the special IFO-PE designs whose speed estimation do not rely on prior position estimate. The input is $\int \hat{\omega} \mathrm{d} t$, the output is $\hat{\omega}$, the model is $(10$, and the generic algorithm is SA5.

The key to implement 21 is to design a feedback loop to force $\hat{e}_{d, \mathrm{ss}}=0$. In other words, if $\hat{e}_{d, \mathrm{ss}} \neq 0$, the speed estimate $\hat{\omega}$ must be updated to make $\hat{e}_{d, \mathrm{ss}}=0$. So the practical implementation of $[21]$ is [85, Sec. III] [117]

$$
s \hat{\theta}_{d}=\hat{\omega}=k \frac{\hat{e}_{q, \mathrm{ss}}}{K_{\mathrm{Active}}}+\operatorname{sign}\left(\hat{e}_{q, \mathrm{ss}}\right) \frac{k_{1} s+k_{2}}{s} \hat{e}_{d, \mathrm{ss}}
$$

Special choices are $k=0$ [3], and $k_{2}=0$ [21], [118]. It is pointed out in [5] that the introduction of an additional LPF will resolve the algebraic loop caused by (30), because $\hat{e}_{q, \mathrm{ss}}$ is a function of $\hat{\omega}$, so $\hat{\omega}$ appears on both side of (30).

${ }^{9}$ The $u_{d}, u_{q}, i_{d}, i_{q}$ used for $\hat{e}_{d, \mathrm{ss}}, \hat{e}_{q, \mathrm{ss}}$ are obtained using IFO: $\boldsymbol{P}\left(\frac{1}{s} \hat{\omega}\right)$.
A variant of 30 is to replace $\hat{e}_{q, \mathrm{ss}}, \hat{e}_{d, \mathrm{ss}}$ with integral of $q$-axis and $d$-axis current error, $\tilde{i}_{d}, \tilde{i}_{q}[85$, Sec. IV]:

$$
\begin{aligned}
& \hat{e}_{q}=k \frac{1}{s}\left[i_{q}-\frac{1}{L_{q} s}\left(\hat{e}_{q, \mathrm{ss}}-\hat{e}_{q}\right)\right] \\
& s \hat{\theta}_{d}=\hat{\omega}=\frac{\hat{e}_{q}}{K_{\mathrm{Active}}}+\frac{k_{1} s+k_{2}}{s}\left[i_{d}-\frac{1}{L_{q} s} \hat{e}_{d, \mathrm{ss}}\right] \\
& \text { with }\left[i_{d}, i_{q}\right]^{\top}=\boldsymbol{P}\left(\hat{\theta}_{d}\right) \boldsymbol{i}
\end{aligned}
$$

where $k_{2}$ is originally set to zero in [85]. Note the current observer is embedded in (31) as $L_{q} s i_{d}=\hat{e}_{q, \mathrm{ss}}-\hat{e}_{q}$ and $L_{q} s \hat{i}_{q}=\hat{e}_{d, \mathrm{ss}}$. As a result, the steady state assumption of $s i_{d}=s i_{q}=0$ for 21) can be removed.

We believe it is one of the most interesting observations in the field of sensorless control, that (when the $K_{\text {Active }}$ is constant,) the open-loop $q$-axis current error in (31a) contains speed error information, and the open-loop $d$-axis current error in (31b) contains position error information [86, Eq. (9.26)]. This is further generalized for time-varying $K_{\text {Active }}$ in [5. Eq. (13)] as "basic relations for sensorless flux estimation".

\section{Magnetic Asymmetry (Rotor Slot Harmonics) Detection}

For straight slot induction motors of certain stator and rotor slot combinations [119], the rotor slotting will induce harmonics in $i$ [120], and rotor speed can be detected from the rotor slot harmonics in $i$ [119], [121], [122]. This kind of speed estimation can detect speed independently from the rotor position and has almost no parameter dependency [121].

\section{Lose the Constant $K_{\text {Active }}$ Assumption}

So far, thanks to the constant $K_{\text {Active }}$ assumption, all the SAs reviewed above (except the ones relying on the magnetic asymmetry) can be applied to both induction motors and PM motors ${ }^{10}$ However, $K_{\text {Active }}$ is by definition a time-varying parameter as long as $\left(L_{d}-L_{q}\right) i_{d}$ varies, and a change in $K_{\text {Active }}$ leads to the unmodelled dynamics $\boldsymbol{E}_{u}$ in (7).

Sometimes a time-varying $K_{\text {Active }}$ is beneficial, e.g., for efficiency improvement or for better dynamic performance. Specifically, at high speeds, faster speed dynamic process can be achieved if the flux amplitude is first weakened such that more dc bus voltage can be used for producing torque current, which is a result of a multi-step optimization control [123].

This section briefly reviews compensation for the disturbance due to time-varying $K_{\text {Active }}$ in salient motors in Sec. VI-A and then the rest of this section focuses on the derivation of induction motor model and its SA designs. In fact, most literature of sensorless induction motors depends on the time-varying $K_{\text {Active }}$ model.

\section{A. Compensation for Time-Varying $K_{\text {Active }}$ in Salient Motors}

In [11], an angle compensation that takes into account the unmodelled dynamics in $(7 \mathrm{~b})$ when $K_{\text {Active }}$ varies is proposed. In [9], the $\dot{i}_{d}$ in the unmodelled dynamics $\boldsymbol{E}_{u}$ in $7 \mathrm{a}$ is compensated by its estimate.

${ }^{10}$ Even though SA1 does not explicitly require $K_{\text {Active }}$ to be constant, but the flux or voltage compensation often relies on the constant $K_{\text {Active }}$ assumption. For example, the flux offset $\hat{D}_{\psi}$ in 24 does not equal to 0 when flux amplitude varies. 


\section{B. Model of Induction Motors with Time-Varying $K_{\text {Active }}$}

For induction motors, the unmodelled dynamics $\boldsymbol{E}_{u}$ satisfy

$$
\boldsymbol{E}_{u}=\boldsymbol{P}^{-1}\left(\theta_{d}\right)\left[\begin{array}{c}
\dot{K}_{\text {Active }} \\
0
\end{array}\right]=R_{\text {req }} \underbrace{\left(\boldsymbol{i}-\frac{\boldsymbol{\psi}_{\text {Active }}}{L_{d}-L_{q}}\right)}_{\text {negative rotor current }}-\omega_{\mathrm{sl}} \boldsymbol{J} \boldsymbol{\psi}_{\text {Active }}
$$

in which (1) and (4) have been substituted, and $\omega_{\mathrm{sl}}=\frac{R_{\mathrm{req}} i_{q}}{K_{\text {Active }}}$ is the slip relation. The model with stator current and active flux as states can be derived from (6), (7a) and (32):

$$
\begin{aligned}
L_{q} \frac{\mathrm{d}}{\mathrm{d} t} \boldsymbol{i} & =\boldsymbol{u}-R \boldsymbol{i}-\frac{\mathrm{d}}{\mathrm{d} t} \boldsymbol{\psi}_{\text {Active }} \\
\frac{\mathrm{d}}{\mathrm{d} t} \boldsymbol{\psi}_{\text {Active }} & =\frac{-R_{\text {req }}}{L_{d}-L_{q}} \boldsymbol{\psi}_{\text {Active }}+R_{\text {req }} \boldsymbol{i}+\left(\omega-\omega_{\mathrm{sl}}\right) \boldsymbol{J} \boldsymbol{\psi}_{\text {Active }}
\end{aligned}
$$

which is exactly the inverse- $\Gamma$ circuit induction motor model. There are two things that make induction motors unique:

1) Active flux amplitude $K_{\text {Active }}$ is not constant and is maintained by stator excitation for non-PM motors.

2) There is a slip speed $\omega_{\mathrm{sl}}$ difference between field speed $\omega$ and rotor speed $\omega_{r}$, i.e., $\omega_{r}=\omega-\omega_{\text {sl }}{ }^{11}$

In other words, the induction motor is not a PM motor nor synchronous motor. These two facts correspond to the two unique features of the SAs dedicated for induction motors:

1) There is a chance for estimated flux amplitude $\hat{K}_{\text {Active }}$ to collapse [124], and there is a chance for the change in flux amplitude being mis-interpreted as a change in flux angle [5], such that unstable sensorless operation results.

2) The current model of induction motor 33b provides angle information, while for synchronous motors, the angle of current model flux can not be utilized [5] (10)]. Therefore, in the context of PM motors, the term "current model" is no more than the active flux parameter $K_{\text {Active }}$.

\section{SAs Based on $\left(\boldsymbol{i}, \boldsymbol{\psi}_{\text {Active }}\right)$ Model (33)}

1) IS-PE Design: IS-PE is achieved by designing 4th-order DO for the unknown term $\left(\frac{-R_{\text {req }}}{L_{d}-L_{q}}+\omega_{r} \boldsymbol{J}\right) \boldsymbol{\psi}_{\text {Active }}$ in 33 ) using SM correction [106], [107], [109], [125]-[127] or PI law dynamic correction (a.k.a. ESO) [128]. This results in an IS-PE design with a redundant observer as is discussed in the Appendix A. The redundant observer gives an estimate of flux for direct calculation of $\hat{\omega}_{r}$ by [109. Eq. (23)] [129. Eq. (26)], and see also [129, Sec. V] for a cascaded variant of redundant flux observer. Alternatively, one can design an IS SMDO whose correction $f$ is in replace of the unknown term $\omega_{r} \boldsymbol{J} \psi_{s}$ or $\omega_{r} \boldsymbol{J} \psi_{\text {Active }}$, depending on the choice of state variables [130].

2) Non-IS-PE Design: Using current and flux as states, speed-adaptive observer can be designed in $\alpha \beta$-frame [83], [108], [131]-[137] and $d q$-frame [138]. This is referred in literature as the "full-order observer" of induction motors, which has attracted a lot of research attention. Active flux (or rotor flux) is often chosen as the state, while stator flux $\psi_{s}$ can also be selected as state [108]. Linear correction is often used, but SM correction can also be found in literature [83], [108], [136].

\footnotetext{
${ }^{11}$ The slip speed causes an algebraic loop when using 30 for sensorless $q$-axis current control [5].
}

As a special case of non-IS-PE, the motion dynamics (2) can be further utilized such that speed is treated as a state and inertia is needed. In $\alpha \beta$-frame, a 6th-order natural speed observer is proposed in [18] with the stator current, active flux, speed and load torque as states, and the key feature is to use motor active power error as the scalar output error $\varepsilon$. In $d q$-frame, it is stated in [139] that the speed estimation can be achieved through the $d$-axis subsystem, and a 5th-order SM state observer consisting of $d$-axis current, $d$-axis rotor flux, rotor position, rotor speed and load torque is proposed.

3) Challenges at Low Speed Regeneration: It is very challenging to stabilize the $\left(i, \psi_{\text {Active }}\right)$ model based full-order observer in low speed regeneration and slow zero frequency crossing, because the stable speed adaptation law derived from Lyapunov function [133] depends on the unknown flux error, and the hyper-stability analysis in [131] depends on the assumption that the ratio between flux error norm and current error norm has finite upper bound such that the unknown flux error can be replaced by current error. Careful observer gain designs based on the linearized model (see, e.g., [134], [137], [140], [141]) and the positive real property [142] are proposed for improved stability. It is also effective to re-design the speed adaptation law [135], [143], [144] [19, Eq. (26)]. It is shown in [145] that in order to find a Lyapunov function for the fullorder observer, the observer coefficients must be dependent on the actual speed, implying global stable design does not exist.

\section{Change of States for Global Stability}

To attack the regeneration instability challenge, an ideal solution is to find a globally stable speed-adaptive observer design. In the literature of observer design [146]-[150], observer is often proposed for a class of systems that are in Brunovsky observer form [151 12, which does not describe the induction motor dynamics (33). We will soon see that the key to attain global stability is to use a different state variable other than active flux. In the following, we will use $(\boldsymbol{y}, \boldsymbol{x})$ to denote the output state and the internal state of the new model.

1) Model $\left(L_{q} \boldsymbol{i},-\boldsymbol{e}_{\text {Active }}\right)$ : The dynamics are [19]

$$
\begin{aligned}
& s \boldsymbol{y}=\boldsymbol{u}-R \boldsymbol{i}+\boldsymbol{x} \\
& s \boldsymbol{x}=-R_{\text {req }}\left(s \boldsymbol{i}+\frac{1}{L_{d}-L_{q}} \boldsymbol{x}\right)+\omega_{r} \boldsymbol{J} \boldsymbol{x}
\end{aligned}
$$

where $s \boldsymbol{i}$ can be obtained using a state variable filter [19].

2) Model $\left(L_{q} \boldsymbol{i}, R_{\mathrm{req}} \boldsymbol{i}-\boldsymbol{e}_{\text {Active }}\right)$ : The dynamics are [19]

$$
\begin{aligned}
& s \boldsymbol{y}=\boldsymbol{u}-\left(R+R_{\text {req }}\right) \boldsymbol{i}+\boldsymbol{x} \\
& s \boldsymbol{x}=-\left(\frac{R_{\text {req }}}{L_{d}-L_{q}} \boldsymbol{I}-\omega_{r} \boldsymbol{J}\right)\left(\boldsymbol{x}-R_{\text {req }} i\right)
\end{aligned}
$$

which avoids the term $s i$ in (34).

3) $\operatorname{Model}\left(L_{q} \boldsymbol{i}, L_{q} \boldsymbol{i}+\boldsymbol{\psi}_{\text {Active }}\right)$ : This yields

$s \boldsymbol{y}=\boldsymbol{u}-\left(R+R_{\mathrm{req}}\right) \boldsymbol{i}+\left(\frac{R_{\mathrm{req}}}{L_{d}-L_{q}} \boldsymbol{I}-\omega_{r} \boldsymbol{J}\right)(\boldsymbol{x}-\boldsymbol{y})$

$s \boldsymbol{x}=\boldsymbol{u}-R \boldsymbol{i}$

${ }^{12}$ To simply put, the following system form is desired:

$$
\frac{\mathrm{d}}{\mathrm{d} t}\left[\begin{array}{l}
\boldsymbol{y} \\
\boldsymbol{x}
\end{array}\right]=\left[\begin{array}{ll}
\mathbf{0} & \boldsymbol{I} \\
\mathbf{0} & \mathbf{0}
\end{array}\right]\left[\begin{array}{l}
\boldsymbol{y} \\
\boldsymbol{x}
\end{array}\right]+\text { Regressor } \times \text { Parameter }+\ldots
$$


whose key property is that there is no unknown variable $\omega_{r}$ in the dynamics of stator flux $\boldsymbol{x}$. The research based on this model is summarized in the monograph [152].

4) Model $\left(L_{q} \boldsymbol{i},\left[\frac{R_{\mathrm{req}}}{L_{d}-L_{q}} \boldsymbol{I}-\omega_{r} \boldsymbol{J}\right] \boldsymbol{\psi}_{s}\right)$ : This yields [153]

$$
\begin{aligned}
& s \boldsymbol{y}=\boldsymbol{x}-\left(\frac{R_{\mathrm{req}}}{L_{d}-L_{q}} L_{d}+R\right) \boldsymbol{i}+\omega_{r} \boldsymbol{J} \boldsymbol{y}+\boldsymbol{u} \\
& s \boldsymbol{x}=\left(\frac{R_{\mathrm{req}}}{L_{d}-L_{q}} \boldsymbol{I}-\omega_{r} \boldsymbol{J}\right)(\boldsymbol{u}-R \boldsymbol{i})
\end{aligned}
$$

5) Model $\left(L_{q} \boldsymbol{i},\left[\frac{R_{\mathrm{req}}}{L_{d}-L_{q}} \boldsymbol{I}-\omega_{r} \boldsymbol{J}\right] \boldsymbol{\psi}_{s},-s\left[\omega_{r} \boldsymbol{J} \psi_{\text {Active }}\right]\right)$ : If speed and load torque are treated as system states, a sixthorder system results, and a state transformation is proposed to extend the system (37) with a third $\mathbb{R}^{2}$ vector state that is the time derivative of $-\omega_{r} \boldsymbol{J} \boldsymbol{\psi}_{\text {Active }}$ [154].

6) Model $\left(L_{q} \boldsymbol{i}, \quad\left[\frac{R_{\mathrm{req}}}{L_{d}-L_{q}} \boldsymbol{I}-\omega_{r} \boldsymbol{J}\right] \boldsymbol{\psi}_{s}, \omega_{r}, T_{L}\right)$ : A more straightforward model is to extend (37) with two scalar states $\omega_{r}, T_{L}$, that is, no state transformation for $\omega_{r}, T_{L}$ [150].

7) Adaptive Observer Form: In [147], a class of system that allows globally stable adaptive observer design is said to be in the adaptive observer form, which is translated into two requirements on induction motor model, i.e., Brunovsky form and known regressor for speed. Even though only model (37) is in adaptive observer form, the existence of globally stable speed-adaptive observer is an established fact [155], [156].

8) Advances in High Gain Observer Design: The known regressor for speed requirement is removed in the high gain observer design [149]. Application of this high gain observer to (37) is studied in [157], and it can also be applied to (34) or (35). A simulation study in [105] shows the high gain observer design proposed in [154] can identify resistances even in speed transients. The requirement on the partitioned matrix needed in [149], [154] is later removed in [150], which allows one to further design high gain observer for the sixth-order induction motor system with two scalar states $\omega_{r}$ and $T_{L}$ instead of the $\mathbb{R}^{2}$ vector $-s\left[\omega_{r} \boldsymbol{J} \psi_{\text {Active }}\right]$ [150]. The observer design in [150] allows certain nonlinear term like $\omega_{r} \boldsymbol{x}$ to appear, and note both $\omega_{r}$ and $\boldsymbol{x}$ are states, with $s \boldsymbol{x}$ defined in (37).

\section{E. Model Reference Adaptive System (MRAS) for IFO-PE}

In the field of sensorless induction motor drive, MRAS is a jargon for a system with the voltage model (VM) as reference model and the current model (33b) as adjustable model 13

The pioneer work on MRAS in [96] (and also the followup work [129], [158]) is a good example showing the spirit of IFO-PE that an accurate estimate of flux/emf is not needed, by using (28) as the reference model and using high-pass filtered $\boldsymbol{i}$ for current model as the adjustable model. There are also attempts to compensate for the gain and lag introduced in (28) (see, e.g., [159]). The convergence of MRAS based flux estimate needs an analysis of the error dynamics of the flux error and the mismatch between VM and current model [160]. In [12], the VM is transformed to an estimated $d q$ frame to derive a generalized slip relation in terms of the VM correction gains. In [161], the correction in VM is replaced with a super-twisting based dynamic correction. The dual reference observer proposed in [130] is also an MRAS, and is

\footnotetext{
${ }^{13}$ This is the reason why we have been using the name CAO instead of MRAS in Sec. IV-B
}

an example of implementing the amplitude correction (26) in its current error form 25a in a time-varying $K_{\text {Active }}$ model. The MRAS implementation in [27] has made it clear that the amplitude mismatch is used to stabilize VM and the angle mismatch is used to tune $\hat{\omega}$ used in current model. In [129], the speed adaptation law is implemented as an SM control law.

Readers are referred to [162] for a dedicated review of various variants of MRAS that have different output error $\varepsilon$.

\section{CONCLUding REMARKS}

This paper reviews SA designs for both induction motors and PM motors, and a map of the overview is shown in Fig. 4 IS-PE is a key concept in this paper, meaning the PE has no speed-dependency, e.g., saliency based methods. If there is two-way coupling between PE and speed estimation, the PE is non-IS. All speed estimation methods are coupled with PE in some way, with an exception being the rotor slot harmonics based speed detection. According to Fig. 4 , there are four types of generic PE methods:

1) SA1 - the potentially IS DO that does not need the model of the unknown internal states. The key is to design dynamic correction that allows smaller switching gain to reduce chattering for SMDO and reduces lagging when tracking ac disturbance for linear DO.

2) SA2 - the non-IS state observer that utilizes the model of the unknown internal states. The key is to decide which path to go: the robust reduced-order state estimation or the speed-adaptive full-order observer. From (7), emf observer is disturbed by $\dot{\omega}$ while flux observer is not.

3) SA3/4 - the potentially IS stabilized integrator. The key is to design voltage and/or flux compensation based on the three assumptions from prior knowledge, or to implement the integrator as a statically compensated (open-loop) state filter. There is also a trend to design the stabilized voltage model as a non-IS single tune integrator.

4) The IFO integrator $\hat{\theta}_{d}=\frac{1}{s} \hat{\omega}$ that enables IFO based speed estimation that can take advantage of $\boldsymbol{P}\left(\frac{1}{s} \hat{\omega}\right)$.

A complete SA scheme consists of the PE and a cascaded or interconnected speed estimation for which the generic algorithms are SA5-7: direct calculation, MRAS, and speed observer, respectively. Now, we are ready to make some general recommendations by topics as follows.

Regeneration stability. There is no regeneration instability issue for PM motors, because classical SA designs for induction motor allows the intermediate state, i.e., the active/rotor flux, to collapse to zero. In fact, with IS flux estimation, there is no need of working-condition-dependent stabilization design for sensorlesss induction motors anymore. For example, it is mentioned in [105] that the original implementation of the non-IS 6th-order natural observer for current, flux, speed, and load torque in [18], loses its stability during low-speed regeneration, while a simple modification to a cascaded design with IS flux estimator plus a cascaded speed observer resolves this problem.

Adopt the constant $K_{\text {Active }}$ assumption. This is a natural practice for PM motor SA designs. For induction motors, we encourage to design the SA scheme as if $K_{\text {Active }}$ is a 


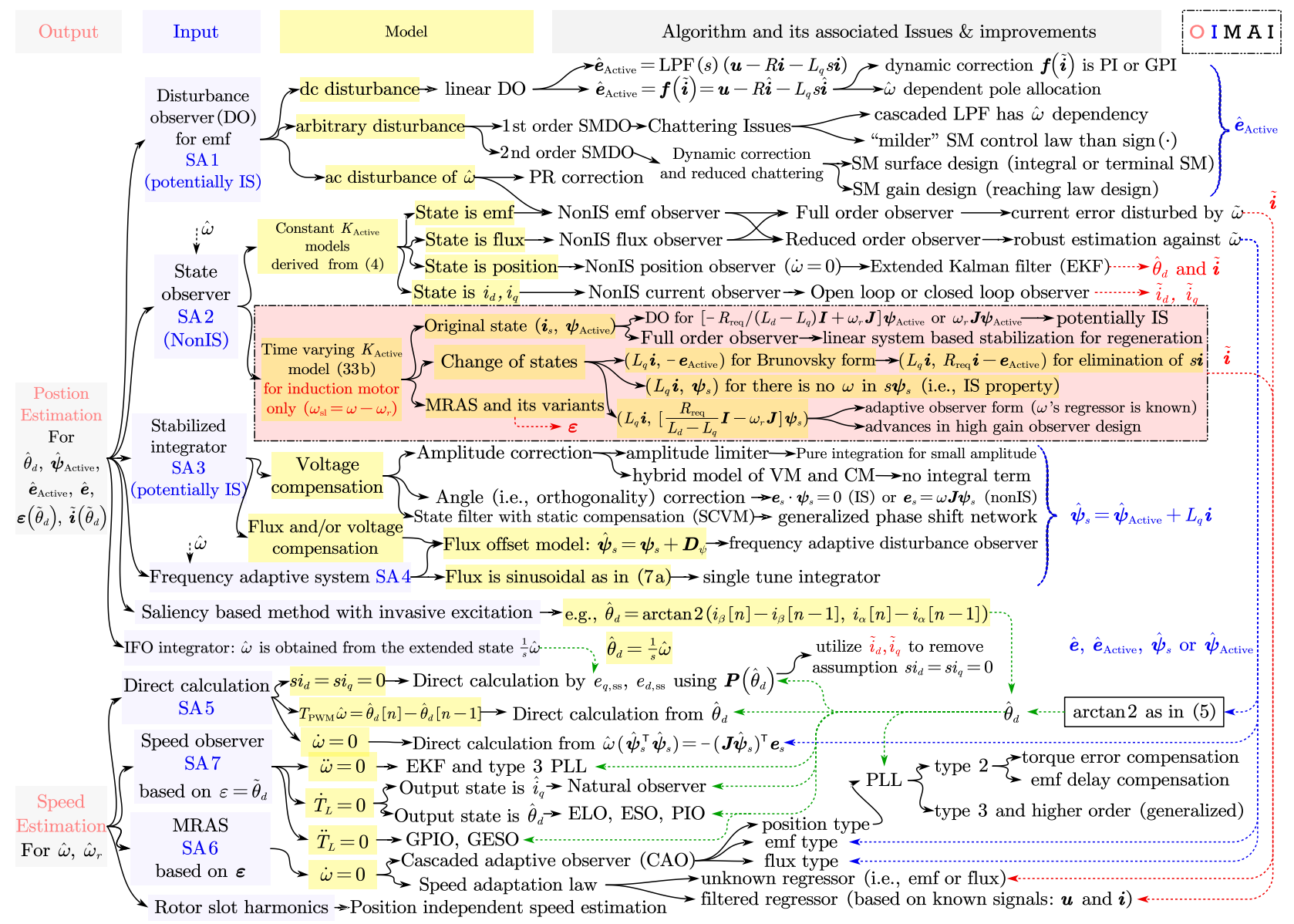

Fig. 4. The map of the overview by the 5 layer hierarchy "O-I-M-A-I". Solid line means classification or logic flow, and dashed line describes the signal flow. The example saliency based method is [110]. Note the non-IS tuning and non-IS variants of SA1/3 discussed in Sec. [III-B and III-C are not shown.

constant while calculating $K_{\text {Active }}$ using (1). In fact, all SAs reviewed in this paper should be able to be applied to induction motor ${ }^{14}$, and there is at least one benefit that the collapse of the estimated flux amplitude can be avoided.

Time-varying $K_{\text {Active }}$ Model. For PM motors, there is a need for more research of the compensation of the SA scheme when constant $K_{\text {Active }}$ assumption is violated. As for induction motors, first, there is also IS-PE design for induction motor model (33a), and an ensuing redundant observer using (33b) shall give the flux angle needed for DFOC (see, e.g., [106], [109]), or this SA design can be easily extended as general IFO-PE; Second, the reality is that for IFOC, only the speed estimate $\hat{\omega}$ is the ultimate goal and this means that even the globally stable speed-adaptive observer (which is non-ISPE) is only an intermediate step to obtain $\hat{\omega}$. Globally stable design is recommended because the observer tuning freedom is not exhausted for stabilization purpose. However, given the fact that the Lyapunov stability analysis is established to only ensure the asymptotically stability of state estimation through the speed adaptation design, an additional cascaded speed estimation that extracts $\hat{\omega}$ from the globally stable state estimation sounds reasonable. In other words, the speed estimate $\hat{\omega}$ is designed to be disturbed by any parameter uncertainty in the model, as an effort to ensure consistent estimation of the state estimation, and therefore, maybe a postPE speed estimation from the state estimation could be more

${ }^{14}$ This even includes the saliency based method, see, e.g., [163]. accurate than the results from the speed adaptation law 15

Try IS algorithm SA1/3 as a starting point. E.g., SA3 with amplitude correction (i.e., the hybrid of VM and current model) is one of the mostly widely used IS-PE. For SA1 with linear correction, we suggest to implement the dynamic correction $f$ to higher order (i.e., as GESO or GPIO) as an effort to reduce the lagging when tracking ac emf disturbance. For SA1 with nonlinear correction $f$, we would like to emphasize that as long as $\kappa_{0}$ [defined in the general DO [45p] is within $[0,1)$, there would be chattering. Therefore, it is also beneficial to implement the SMDO to higher order than second order to reduce chattering, but the SM correction involves more coefficients such as $\kappa_{j}, j=0,1,2$, and the optimal tuning of $\kappa_{j}$ along with correction gains is of interest. As a comparison, non-IS-PE introduces two-way coupling between $\mathrm{PE}$ and speed estimation and the interconnected structure is more difficult to be analyzed.

EMF based PE considering harmonics. First, there is no evidence showing that emf observer is better for PE than flux observer. Also, note the sinusoidal dynamics of emf are disturbed by speed variation $\dot{\omega}$. After emf estimation, a redundant observer can be implemented, which can simply be an integration of the emf, to get a flux estimate for $\hat{\theta}_{d}$, which attenuates the higher-order harmonics in emf estimate

${ }^{15} \mathrm{~A}$ well known example is that the sensorless controlled induction motor can control accurate torque but can only regulate biased speed when rotor resistance value is erroneous, which implies that active flux angle $\hat{\theta}_{d}$ is accurate and $\hat{\omega}$ compensates for the uncertainty in rotor resistance [131], [158]. 
and amplifies the low frequency disturbance in emf estimate. If $\hat{\omega}$ is available, a single tune integrator that is an integrator only at $\hat{\omega}$-frequency can be used to reduce both dc-bias and higher-order harmonics, where the key step is to design a good band-pass filter [59].

Speed Estimation. Direction calculation (IFO-SA5) needs very little computational resources thus is recommended for cheap chips, but it is also sensitive to noises. For high dynamic performance, the SA7 (speed observer) should be used instead of SA6 (MRAS). To reject time-varying load torque, higherorder SA7 design such as GPIO and GESO is beneficial.

\section{APPENDIX A}

\section{Position Estimator DESIGN BASICS}

Even though ac motor is a multiple-input multiple-output (MIMO) system, but the following single-input single-output (SISO) observer design can be generalized to ac motor.

Consider an SISO system with unknown parameter $\omega$ :

$$
\begin{aligned}
& \frac{\mathrm{d}}{\mathrm{d} t} y_{\alpha}=f\left(y_{\alpha}\right)+\frac{\mathrm{d}}{\mathrm{d} t} x_{\alpha}=f\left(y_{\alpha}\right)+g\left(y_{\alpha}, x_{\alpha}, \omega\right) \\
& \frac{\mathrm{d}}{\mathrm{d} t} x_{\alpha}=g\left(y_{\alpha}, x_{\alpha}, \omega\right)
\end{aligned}
$$

with two states, i.e., one measurable output state $y_{\alpha}$ (i.e., the $\alpha$-axis current) and one unknown internal state $x_{\alpha}$ (i.e., the $\alpha$-axis active flux).

Our target is to reconstruct an estimate of $x_{\alpha}$, denoted by $\hat{x}_{\alpha}$, or an estimate of $\dot{x}_{\alpha}$, denoted by $\hat{\dot{x}}_{\alpha}$. If we treat emf $\dot{x}_{\alpha}$ as dc disturbance ${ }^{16}$, the proportional-integral correction is sufficient to reject the disturbance with $k_{1}, k_{2} \geq 0$ :

$$
\mathrm{d} d \hat{y}_{\alpha}=f\left(\hat{y}_{\alpha}\right)+\hat{\dot{x}}_{\alpha}, \quad \hat{\dot{x}}_{\alpha}=k_{1} \tilde{y}_{\alpha}+k_{2} \int \tilde{y}_{\alpha} \mathrm{d} t,
$$

where $\tilde{y}_{\alpha} \triangleq y_{\alpha}-\hat{y}_{\alpha}$ is output error, and non-zero $k_{2}$ leads to dynamic correction-meaning that the observer system is extended with an additional state in the correction term $\hat{\dot{x}}_{\alpha}$. If $\dot{x}_{\alpha}$ is an ac disturbance of frequency $\hat{\omega}$, the proportionalresonant (PR) law that serves as a generalized integrator at a given frequency $\hat{\omega}$ can be used to reject the disturbance:

$$
\frac{\mathrm{d}}{\mathrm{d} t} \hat{y}_{\alpha}=f\left(\hat{y}_{\alpha}\right)+\hat{\dot{x}}_{\alpha}, \quad \hat{\dot{x}}_{\alpha}=k_{1} \tilde{y}_{\alpha}+k_{2} \frac{s}{s^{2}+\hat{\omega}^{2}} \tilde{y}_{\alpha}
$$

If $\dot{x}_{\alpha}$ is the sum of multiple ac disturbances, or if we acknowledge the fact that $\hat{\omega}$ is erroneous, the variable structure correction can be used e.g., with the simplest SM surface $\tilde{y}_{\alpha}$ : $\frac{\mathrm{d}}{\mathrm{d} t} \hat{y}_{\alpha}=f\left(\hat{y}_{\alpha}\right)+\hat{\dot{x}}_{\alpha}, \quad \hat{\dot{x}}_{\alpha}=k_{1} \operatorname{sign}\left(\tilde{y}_{\alpha}\right)+k_{2} \int \operatorname{sign}\left(\tilde{y}_{\alpha}\right) \mathrm{d} t$

Nonzero $k_{1}$ causes chattering, and nonzero $k_{2}$ leads to dynamic correction. Additionally, one can add a redundant state observer for $x_{\alpha}$ to attenuate noises:

$$
\frac{\mathrm{d}}{\mathrm{d} t} \hat{x}_{\alpha}=\hat{\dot{x}}_{\alpha} \text {, with } \hat{\dot{x}}_{\alpha} \text { defined in (39), 40, or 41. }
$$

Alternatively, if we treat $x_{\alpha}$ as a state ${ }^{17}$, a Luenberger state observer for $\hat{x}_{\alpha}$ is established:

$$
\begin{aligned}
& \frac{\mathrm{d}}{\mathrm{d} t} \hat{y}_{\alpha}=k_{1} \tilde{y}_{\alpha}+g\left(\hat{y}_{\alpha}, \hat{x}_{\alpha}, \hat{\omega}\right)+f\left(\hat{y}_{\alpha}\right) \\
& \frac{\mathrm{d}}{\mathrm{d} t} \hat{x}_{\alpha}=k_{2} \tilde{y}_{\alpha}+g\left(\hat{y}_{\alpha}, \hat{x}_{\alpha}, \hat{\omega}\right)
\end{aligned}
$$

${ }^{16}$ By "disturbance", we mean we pretend to not know the dynamics of $\dot{x}_{\alpha}$.

${ }^{17}$ By "state", we mean we know at least an approximation of its dynamics.
If we treat $\dot{x}_{\alpha}$ as a state, another state observer that is in the Brunovsky form can be designed:

$$
\begin{aligned}
& \frac{\mathrm{d}}{\mathrm{d} t} \hat{y}_{\alpha}=k_{1} \tilde{y}_{\alpha}+f\left(\hat{y}_{\alpha}\right)+\hat{\dot{x}}_{\alpha} \\
& \frac{\mathrm{d}}{\mathrm{d} t} \hat{\dot{x}}_{\alpha}=k_{2} \tilde{y}_{\alpha}+\frac{\mathrm{d}}{\mathrm{d} t} g\left(\hat{y}_{\alpha}, \hat{x}_{\alpha}, \hat{\omega}\right)
\end{aligned}
$$

In (42) and (43), an estimate of $\hat{\omega}$ is needed, and one can either introduce an adaptive law as $\frac{\mathrm{d}}{\mathrm{d} t} \hat{\omega} \propto \tilde{y}_{\alpha}$, or make sure the state estimate is robust against parameter error $\tilde{\omega}=\omega-\hat{\omega}$.

So far, among (39)- 43), (39) and (41) have the potential to avoid $\hat{\omega}$-dependency. There exists another $\hat{\omega}$-free design, i.e., directly integrate for $z_{\alpha} \triangleq x_{\alpha}+y_{\alpha}$ (i.e., stator flux):

$$
\frac{\mathrm{d}}{\mathrm{d} t} \hat{z}_{\alpha}=\frac{\mathrm{d}}{\mathrm{d} t}\left(\hat{x}_{\alpha}+y_{\alpha}\right)=f\left(y_{\alpha}\right)+\hat{D}_{\alpha}
$$

where the voltage compensation $\hat{D}_{\alpha}$ is included to stabilize the pure integration as there is no $z_{\alpha}$ on the right hand side. For this SISO system, since $\tilde{z}_{\alpha}$ is unknown, we need to design $\hat{D}_{\alpha}$ with some prior knowledge that is solely related to the $\alpha$ axis dynamics. For example, the maximum and minimum of $\hat{z}_{\alpha}$-waveform within one electrical cycle should add to zero at steady state. Here, note the electrical cycle can be determined by detecting adjacent zero-crossings of the $\hat{z}_{\alpha}$-waveform. For a MIMO system, we can use even more prior knowledge, e.g., the orthogonality and the flux amplitude, to constraint the behavior of $\hat{z}_{\alpha}$ as an effort to stabilize the pure integration.

Note (44) corrects the integration within the integrator dynamics, and we can also correct the integration at its output by $\hat{z}_{\alpha}-\hat{D}_{\alpha \psi}$, where the flux compensation $\hat{D}_{\alpha \psi}$ can be either directly calculated by the prior knowledge [23], or can be estimated by a disturbance observer [13].

\section{APPENDIX B}

\section{SpeEd Estimator Design Basics}

Disturbance observer (DO) can be used for extracting speed information from rotor position estimate (denoted by $\vartheta \triangleq \hat{\theta}_{d}$ ), and can be described as a 3rd-order system with four terms:

$$
\begin{aligned}
\frac{\mathrm{d}}{\mathrm{d} t} \hat{\vartheta}=f(\hat{\vartheta}) & +k_{0}|\tilde{\vartheta}|^{\kappa_{0}} \operatorname{sign}(\tilde{\vartheta}) \\
& +k_{1} \int|\tilde{\vartheta}|^{\kappa_{1}} \operatorname{sign}(\tilde{\vartheta}) \mathrm{d} t \\
& +k_{2} \iint|\tilde{\vartheta}|^{\kappa_{2}} \operatorname{sign}(\tilde{\vartheta}) \mathrm{d} t \mathrm{~d} t
\end{aligned}
$$

If $f=k_{2}=0$, constant speed is assumed. If $f=0$, ramp speed is assumed. If $f(\vartheta)=\frac{n_{\mathrm{pp}}}{J_{s}} \int T_{\mathrm{em}}(\vartheta) \mathrm{d} t$, 45 is inertiadependent, and constant load torque is assumed. 45) describes a class of observer designs (with integer $j=0,1,2$ ):

- If $\kappa_{j} \neq 1,45$ is nonlinear ESO. Typical choices are $\kappa_{0}=1, \kappa_{1}=\frac{1}{2}, \kappa_{2}=\frac{1}{4}$ [164, Ch. 4].

- If $\kappa_{j}=1$, 45 is linear ESO, proportional-integral observer (PIO), or extended Luenberger observer (ELO).

- If $\kappa_{j}=1, f=0$, (45) is EKF in which $k_{0}, k_{1}, k_{2}$ are time-varying gains considering the unmodelled noises.

- If $\kappa_{j}=1, k_{2}=f=0$, (45) is PLL or adaptive observer.

- If $\kappa_{j}=k_{1}=k_{2}=f=0$, 45 is first-order SMDO.

- If $\kappa_{1}=k_{2}=f=0, \kappa_{0}=\frac{1}{2}, 45$ is second-order SMDO with dynamic correction using super-twisting algorithm.

Remark 5: 45 can be further generalized to fourth-order system with a " $k_{3}$ term" added, which is making the $\ddot{T}_{L}=0$ 
assumption, which is studied in literature as generalized PI observer (GPIO) [165], [166] or generalized ESO (GESO) [167].

The speed observer (i.e., SA7) takes the following form:

$\hat{\omega}=f(\hat{\vartheta})+k_{1} \int|\tilde{\vartheta}|^{\kappa_{1}} \operatorname{sign}(\tilde{\vartheta}) \mathrm{d} t+k_{2} \iint|\tilde{\vartheta}|^{\kappa_{2}} \operatorname{sign}(\tilde{\vartheta}) \mathrm{d} t \mathrm{~d} t$

\section{REFERENCES}

[1] I. Boldea, M. C. Paicu, and G. Andreescu, "Active flux concept for motion-sensorless unified ac drives," IEEE Transactions on Power Electronics, vol. 23, no. 5, pp. 2612-2618, 2008.

[2] J. Chen, J. Mei, X. Yuan, Y. Zuo, and C. H. T. Lee, "Natural speed observer for nonsalient ac motors," IEEE Transactions on Power Electronics, pp. 1-1, 2021.

[3] B.-H. Bae, S.-K. Sul, J.-H. Kwon, and J.-S. Byeon, "Implementation of sensorless vector control for super-high-speed pmsm of turbocompressor," IEEE Transactions on Industry Applications, vol. 39, no. 3, pp. 811-818, 2003.

[4] M. Pacas, "Sensorless drives in industrial applications," IEEE Industrial Electronics Magazine, vol. 5, no. 2, pp. 16-23, jun 2011.

[5] L. Harnefors, M. Jansson, R. Ottersten, and K. Pietilainen, "Unified sensorless vector control of synchronous and induction motors," IEEE Transactions on Industrial Electronics, vol. 50, no. 1, pp. 153-160, 2003.

[6] Z. Chen, M. Tomita, S. Doki, and S. Okuma, "An extended electromotive force model for sensorless control of interior permanent-magnet synchronous motors," IEEE Transactions on Industrial Electronics, vol. 50, no. 2, pp. 288-295, Apr 2003.

[7] G. R. Slemon, "Modelling of induction machines for electric drives," IEEE Transactions on Industry Applications, vol. 25, no. 6, pp. 11261131, Nov 1989

[8] R. Ortega, N. Barabanov, G. Escobar, and E. Valderrama, "Direct torque control of induction motors: stability analysis and performance improvement," IEEE Transactions on Automatic Control, vol. 46, no. 8, pp. 1209-1222, Aug 2001.

[9] S. Koonlaboon and S. Sangwongwanich, "Sensorless control of interior permanent-magnet synchronous motors based on a fictitious permanent-magnet flux model," in Fourtieth IAS Annual Meeting. Conference Record of the 2005 Industry Applications Conference, 2005. IEEE, 2005.

[10] M. Hasegawa and K. Matsui, "Position sensorless control for interior permanent magnet synchronous motor using adaptive flux observer with inductance identification," IET Electric Power Applications, vol. 3, no. 3, p. 209, 2009.

[11] Y. Zhao, Z. Zhang, W. Qiao, and L. Wu, "An extended flux modelbased rotor position estimator for sensorless control of salient-pole permanent-magnet synchronous machines," IEEE Transactions on Power Electronics, vol. 30, no. 8, pp. 4412-4422, aug 2015.

[12] L. Harnefors, "Design and analysis of general rotor-flux-oriented vector control systems," IEEE Transactions on Industrial Electronics, vol. 48, no. 2, pp. 383-390, April 2001.

[13] Y. Park and S. K. Sul, "Sensorless control method for pmsm based on frequency-adaptive disturbance observer," IEEE Journal of Emerging and Selected Topics in Power Electronics, vol. 2, no. 2, pp. 143-151, June 2014.

[14] S. Shinnaka, "New "d-state-observer"-based vector control for sensorless drive of permanent-magnet synchronous motors," IEEE Transactions on Industry Applications, vol. 41, no. 3, pp. 825-833, may 2005.

[15] S. Bolognani, L. Tubiana, and M. Zigliotto, "Extended kalman filter tuning in sensorless pmsm drives," IEEE Transactions on Industry Applications, vol. 39, no. 6, pp. 1741-1747, 2003.

[16] R. Dhaouadi, N. Mohan, and L. Norum, "Design and implementation of an extended kalman filter for the state estimation of a permanent magnet synchronous motor," IEEE Transactions on Power Electronics, vol. 6, no. 3, pp. 491-497, 1991.

[17] L. Zhao, J. Huang, H. Liu, B. Li, and W. Kong, "Second-order slidingmode observer with online parameter identification for sensorless induction motor drives," Industrial Electronics, IEEE Transactions on, vol. 61, no. 10, pp. 5280-5289, 2014.

[18] S. R. Bowes, A. Sevinc, and D. Holliday, "New natural observer applied to speed-sensorless dc servo and induction motors," IEEE Transactions on Industrial Electronics, vol. 51, no. 5, pp. 1025-1032, Oct 2004.
[19] J. Chen and J. Huang, "Stable simultaneous stator and rotor resistances identification for speed sensorless im drives: Review and new results," IEEE Transactions on Power Electronics, vol. 33, no. 10, pp. 86958709, Oct 2018.

[20] C. J. Volpato Filho and R. P. Vieira, "Adaptive full-order observer analysis and design for sensorless interior permanent magnet synchronous motors drives," IEEE Transactions on Industrial Electronics, pp. 1-1, 2020.

[21] M. Jansson, L. Harnefors, O. Wallmark, and M. Leksell, "Synchronization at startup and stable rotation reversal of sensorless nonsalient pmsm drives," IEEE Transactions on Industrial Electronics, vol. 53, no. 2, pp. 379-387, 2006.

[22] M. Rahman, L. Zhong, M. Haque, and M. Rahman, "A direct torquecontrolled interior permanent-magnet synchronous motor drive without a speed sensor," IEEE Transactions on Energy Conversion, vol. 18, no. 1, pp. 17-22, 2003

[23] R. Wu and G. Slemon, "A permanent magnet motor drive without a shaft sensor," IEEE Transactions on Industry Applications, vol. 27, no. 5 , pp. $1005-1011,1991$

[24] J. Hu and B. Wu, "New integration algorithms for estimating motor flux over a wide speed range," IEEE Transactions on Power Electronics, vol. 13, no. 5, pp. 969-977, Sep 1998.

[25] J. Holtz and J. Quan, "Drift- and parameter-compensated flux estimator for persistent zero-stator-frequency operation of sensorlesscontrolled induction motors," IEEE Transactions on Industry Applications, vol. 39, no. 4, pp. 1052-1060, July 2003.

[26] J. Chen, J. Mei, X. Yuan, Y. Zuo, J. Zhu, and C. H. T. Lee, "Online adaptation of two-parameter inverter modelin sensorless motor drives," IEEE Transactions on Industrial Electronics, 2021 (to be published).

[27] C. Lascu, I. Boldea, and F. Blaabjerg, "A modified direct torque control for induction motor sensorless drive," IEEE Transactions on Industry Applications, vol. 36, no. 1, pp. 122-130, 2000.

[28] C. Lascu and G. . Andreescu, "Sliding-mode observer and improved integrator with dc-offset compensation for flux estimation in sensorlesscontrolled induction motors," IEEE Transactions on Industrial Electronics, vol. 53, no. 3, pp. 785-794, 2006.

[29] G.-D. Andreescu, C. Pitic, F. Blaabjerg, and I. Boldea, "Combined flux observer with signal injection enhancement for wide speed range sensorless direct torque control of IPMSM drives," IEEE Transactions on Energy Conversion, vol. 23, no. 2, pp. 393-402, jun 2008.

[30] A. K. Jain and V. T. Ranganathan, "Modeling and field oriented control of salient pole wound field synchronous machine in stator flux coordinates," IEEE Transactions on Industrial Electronics, vol. 58 , no. 3, pp. 960-970, mar 2011.

[31] S.-C. Agarlita, I. Boldea, and F. Blaabjerg, "High-frequency-injectionassisted "active-flux"-based sensorless vector control of reluctance synchronous motors, with experiments from zero speed," IEEE Transactions on Industry Applications, vol. 48, no. 6, pp. 1931-1939, 2012.

[32] F. J. W. Barnard, W. T. Villet, and M. J. Kamper, "Hybrid activeflux and arbitrary injection position sensorless control of reluctance synchronous machines," in 2014 International Symposium on Power Electronics, Electrical Drives, Automation and Motion. IEEE, jun 2014

[33] A. Yousefi-Talouki, P. Pescetto, and G. Pellegrino, "Sensorless direct flux vector control of synchronous reluctance motors including standstill, MTPA, and flux weakening," IEEE Transactions on Industry Applications, vol. 53, no. 4, pp. 3598-3608, jul 2017.

[34] H.-S. Kim, S.-K. Sul, H. Yoo, and J. Oh, "Distortion-Minimizing Flux Observer for IPMSM Based on Frequency-Adaptive Observers," IEEE Transactions on Power Electronics, vol. 35, no. 2, pp. 2077-2087, Feb. 2020 .

[35] H. Wang, Y. Yang, D. Chen, X. Ge, S. Li, and Y. Zuo, "Speedsensorlss control of induction motors with an open-loop synchronization method," IEEE Journal of Emerging and Selected Topics in Power Electronics, pp. 1-1, 2021.

[36] J. Lee, J. Hong, K. Nam, R. Ortega, L. Praly, and A. Astolfi, "Sensorless control of surface-mount permanent-magnet synchronous motors based on a nonlinear observer," IEEE Transactions on Power Electronics, vol. 25, no. 2, pp. 290-297, feb 2010.

[37] R. Ortega, L. Praly, A. Astolfi, J. Lee, and K. Nam, "Estimation of rotor position and speed of permanent magnet synchronous motors with guaranteed stability," IEEE Transactions on Control Systems Technology, vol. 19, no. 3, pp. 601-614, 2011.

[38] T. Ohtani, N. Takada, and K. Tanaka, "Vector control of induction motor without shaft encoder," IEEE Transactions on Industry Applications, vol. 28, no. 1, pp. 157-164, Jan 1992. 
[39] J. Holtz and J. Quan, "Sensorless vector control of induction motors at very low speed using a nonlinear inverter model and parameter identification," IEEE Transactions on Industry Applications, vol. 38, no. 4, pp. 1087-1095, Jul 2002.

[40] T. Senjyu, T. Shingaki, and K. Uezato, "Sensorless vector control of synchronous reluctance motors with disturbance torque observer," in APEC 2000. Fifteenth Annual IEEE Applied Power Electronics Conference and Exposition (Cat. No.00CH37058). IEEE, 2000.

[41] S. Chi, Z. Zhang, and L. Xu, "Sliding-mode sensorless control of directdrive pm synchronous motors for washing machine applications," IEEE Transactions on Industry Applications, vol. 45, no. 2, pp. 582-590, 2009

[42] H. Kim, J. Son, and J. Lee, "A high-speed sliding-mode observer for the sensorless speed control of a pmsm," IEEE Transactions on Industrial Electronics, vol. 58, no. 9, pp. 4069-4077, Sept 2011.

[43] Z. Qiao, T. Shi, Y. Wang, Y. Yan, C. Xia, and X. He, "New slidingmode observer for position sensorless control of permanent-magnet synchronous motor," IEEE Transactions on Industrial Electronics, vol. 60, no. 2, pp. 710-719, Feb 2013.

[44] L. Zhang, Y. Fan, C. Li, A. Nied, and M. Cheng, "Fault-tolerant sensorless control of a five-phase FTFSCW-IPM motor based on a widespeed strong-robustness sliding mode observer," IEEE Transactions on Energy Conversion, vol. 33, no. 1, pp. 87-95, mar 2018.

[45] K.-L. Kang, J.-M. Kim, K.-B. Hwang, and K.-H. Kim, "Sensorless control of pmsm in high speed range with iterative sliding mode observer," in Nineteenth Annual IEEE Applied Power Electronics Conference and Exposition, 2004. APEC'04., vol. 2. IEEE, 2004 pp. 1111-1116.

[46] Y. Feng, J. Zheng, X. Yu, and N. V. Truong, "Hybrid terminal slidingmode observer design method for a permanent-magnet synchronous motor control system," IEEE Transactions on Industrial Electronics, vol. 56, no. 9, pp. 3424-3431, 2009.

[47] A. Apte, V. A. Joshi, H. Mehta, and R. Walambe, "Disturbanceobserver-based sensorless control of PMSM using integral state feedback controller," IEEE Transactions on Power Electronics, vol. 35, no. 6, pp. 6082-6090, jun 2020.

[48] H. Lee and J. Lee, "Design of iterative sliding mode observer for sensorless PMSM control," IEEE Transactions on Control Systems Technology, vol. 21, no. 4, pp. 1394-1399, jul 2013.

[49] D. Zaltni, M. Ghanes, J. P. Barbot, and M. N. Abdelkrim, "A HOSM observer with an improved zero-speed position estimation design for surface PMSM sensor-less control," in 2010 IEEE International Conference on Control Applications. IEEE, sep 2010.

[50] D. Liang, J. Li, R. Qu, and W. Kong, "Adaptive second-order slidingmode observer for pmsm sensorless control considering vsi nonlinearity," IEEE Transactions on Power Electronics, vol. 33, no. 10, pp. 8994-9004, Oct 2018.

[51] A. T. Woldegiorgis, X. Ge, S. Li, and M. Hassan, "Extended sliding mode disturbance observer-based sensorless control of IPMSM for medium and high-speed range considering railway application," IEEE Access, vol. 7, pp. 175 302-175 312, 2019.

[52] W. Xu, S. Qu, L. Zhao, and H. Zhang, "An improved adaptive sliding mode observer for middle- and high-speed rotor tracking," IEEE Transactions on Power Electronics, vol. 36, no. 1, pp. 1043-1053, jan 2021.

[53] S. Chung, "Robust speed control of brushless direct-drive motor using integral variable structure control," IEE Proceedings - Electric Power Applications, vol. 142, no. 6, p. 361, 1995.

[54] I. Sami, S. Ullah, A. Basit, N. Ullah, and J.-S. Ro, "Integral super twisting sliding mode based sensorless predictive torque control of induction motor," IEEE Access, vol. 8, pp. 186740-186755, 2020.

[55] M. Zhou, S. Cheng, Y. Feng, W. Xu, L. Wang, and W. Cai, "Full-order terminal sliding-mode based sensorless control of induction motor with gain adaptation," IEEE Journal of Emerging and Selected Topics in Power Electronics, pp. 1-1, 2021.

[56] M. Tomita, T. Senjyu, S. Doki, and S. Okuma, "New sensorless control for brushless dc motors using disturbance observers and adaptive velocity estimations," IEEE Transactions on Industrial Electronics, vol. 45, no. 2, pp. 274-282, Apr 1998.

[57] C. J. Volpato Filho and R. P. Vieira, "Pole placement design methodology of back-emf adaptive observer for sensorless pmsm drives," Journal of Control, Automation and Electrical Systems, vol. 31, no. 1, pp. 84-93, 2020

[58] F. Jiang, S. Sun, A. Liu, Y. Xu, Z. Li, X. Liu, and K. Yang, "Robustness improvement of model-based sensorless SPMSM drivers based on an adaptive extended state observer and an enhanced quadrature PLL,"
IEEE Transactions on Power Electronics, vol. 36, no. 4, pp. 48024814, apr 2021.

[59] C. J. V. Filho, D. Xiao, R. P. Vieira, and A. Emadi, "Observers for highspeed sensorless PMSM drives: Design methods, tuning challenges and future trends," IEEE Access, vol. 9, pp. 56397-56415, 2021.

[60] W. Zhao, S. Jiao, Q. Chen, D. Xu, and J. Ji, "Sensorless control of a linear permanent-magnet motor based on an improved disturbance observer," IEEE Transactions on Industrial Electronics, vol. 65, no. 12 , pp. 9291-9300, dec 2018 .

[61] D. Xiao, S. Nalakath, Y. Sun, J. Wiseman, and A. Emadi, "Complexcoefficient adaptive disturbance observer for position estimation of IPMSMs with robustness to DC errors," IEEE Transactions on Industrial Electronics, vol. 67, no. 7, pp. 5924-5935, jul 2020.

[62] S. Sul, Y. Kwon, and Y. Lee, "Sensorless control of ipmsm for last 10 years and next 5 years," CES Transactions on Electrical Machines and Systems, vol. 1, no. 2, pp. 91-99, 2017.

[63] G. Wang, M. Valla, and J. Solsona, "Position sensorless permanent magnet synchronous machine drives-a review," IEEE Transactions on Industrial Electronics, vol. 67, no. 7, pp. 5830-5842, 2020.

[64] V. Repecho, J. Waqar, D. Biel, and A. Doria-Cerezo, "Zero speed sensorless scheme for PMSM under decoupled sliding mode control," IEEE Transactions on Industrial Electronics, pp. 1-1, 2021.

[65] C. Silva, G. Asher, and M. Sumner, "Hybrid rotor position observer for wide speed-range sensorless PM motor drives including zero speed,' IEEE Transactions on Industrial Electronics, vol. 53, no. 2, pp. 373378, apr 2006

[66] A. Piippo, J. Salomaki, and J. Luomi, "Signal injection in sensorless PMSM drives equipped with inverter output filter," in 2007 Power Conversion Conference - Nagoya. IEEE, apr 2007.

[67] A. Piippo, M. Hinkkanen, and J. Luomi, "Analysis of an adaptive observer for sensorless control of interior permanent magnet synchronous motors," IEEE Transactions on Industrial Electronics, vol. 55, no. 2, pp. 570-576, 2008.

[68] G. Wang, R. Yang, and D. Xu, "DSP-based control of sensorless IPMSM drives for wide-speed-range operation," IEEE Transactions on Industrial Electronics, vol. 60, no. 2, pp. 720-727, feb 2013.

[69] G. Foo and M. Rahman, "Sensorless sliding-mode MTPA control of an IPM synchronous motor drive using a sliding-mode observer and HF signal injection," IEEE Transactions on Industrial Electronics, vol. 57, no. 4 , pp. 1270-1278, apr 2010.

[70] S. Sayeef, G. Foo, and M. F. Rahman, "Rotor position and speed estimation of a variable structure direct-torque-controlled IPM synchronous motor drive at very low speeds including standstill," IEEE Transactions on Industrial Electronics, vol. 57, no. 11, pp. 3715-3723, nov 2010.

[71] B. Du, S. Wu, S. Han, and S. Cui, "Application of linear active disturbance rejection controller for sensorless control of internal permanentmagnet synchronous motor," IEEE Transactions on Industrial Electronics, vol. 63, no. 5, pp. 3019-3027, may 2016.

[72] A. Yousefi-Talouki, P. Pescetto, G. Pellegrino, and I. Boldea, "Combined active flux and high-frequency injection methods for sensorless direct-flux vector control of synchronous reluctance machines," IEEE Transactions on Power Electronics, vol. 33, no. 3, pp. 2447-2457, mar 2018.

[73] M. X. Bui, M. F. Rahman, and D. Xiao, "A hybrid sensorless controller of an interior permanent magnet synchronous machine using current derivative measurements and a sliding mode observer," IEEE Transactions on Industry Applications, vol. 56, no. 1, pp. 314-324, 2020.

[74] N. Bianchi, S. Bolognani, J.-H. Jang, and S.-K. Sul, "Advantages of inset pm machines for zero-speed sensorless position detection," IEEE Transactions on Industry Applications, vol. 44, no. 4, pp. 1190-1198, 2008.

[75] N. Bianchi and S. Bolognani, "Sensorless-oriented-design of PM motors," in 2007 IEEE Industry Applications Annual Meeting. IEEE, sep 2007.

[76] Y. Kano, "Sensorless-oriented design of ipmsm," in 2014 International Power Electronics Conference (IPEC-Hiroshima 2014 - ECCE ASIA), 2014, pp. 2457-2464.

[77] Z. Xu and M. Rahman, "An adaptive sliding stator flux observer for a direct-torque-controlled IPM synchronous motor drive," IEEE Transactions on Industrial Electronics, vol. 54, no. 5, pp. 2398-2406, oct 2007.

[78] M. Kim and S.-K. Sul, "An enhanced sensorless control method for PMSM in rapid accelerating operation," in The 2010 International Power Electronics Conference - ECCE ASIA -. IEEE, jun 2010.

[79] S. Bolognani, S. Calligaro, and R. Petrella, "Design issues and estimation errors analysis of back-EMF based position and speed observer for 
SPM synchronous motors," in 2011 Symposium on Sensorless Control for Electrical Drives. IEEE, sep 2011.

[80] Z. Xu and M. F. Rahman, "Comparison of a sliding observer and a kalman filter for direct-torque-controlled IPM synchronous motor drives," IEEE Transactions on Industrial Electronics, vol. 59, no. 11, pp. 4179-4188, nov 2012.

[81] G. Wang, Z. Li, G. Zhang, Y. Yu, and D. Xu, "Quadrature PLLbased high-order sliding-mode observer for IPMSM sensorless control with online MTPA control strategy," IEEE Transactions on Energy Conversion, vol. 28, no. 1, pp. 214-224, mar 2013.

[82] S. Ye and X. Yao, "A modified flux sliding-mode observer for the sensorless control of PMSMs with online stator resistance and inductance estimation," IEEE Transactions on Power Electronics, vol. 35, no. 8, pp. 8652-8662, aug 2020 .

[83] S. Doki, S. Sangwongwanich, and S. Okuma, "Implementation of speed-sensor-less field-oriented vector control using adaptive sliding observers," in Proceedings of the 1992 International Conference on Industrial Electronics, Control, Instrumentation, and Automation, Nov 1992, pp. 453-458 vol.1.

[84] T. J. Vyncke, R. K. Boel, and J. A. A. Melkebeek, "On extended kalman filters with augmented state vectors for the stator flux estimation in SPMSMs," in 2010 Twenty-Fifth Annual IEEE Applied Power Electronics Conference and Exposition (APEC). IEEE, feb 2010.

[85] N. Matsui, "Sensorless pm brushless dc motor drives," IEEE Transactions on Industrial Electronics, vol. 43, no. 2, pp. 300-308, April 1996

[86] K. H. Nam, AC Motor Control and Electrical Vehicle Applications (1st ed.). CRC Press, 2010.

[87] C. Lascu and G.-D. Andreescu, "PLL position and speed observer with integrated current observer for sensorless PMSM drives," IEEE Transactions on Industrial Electronics, vol. 67, no. 7, pp. 5990-5999, jul 2020.

[88] J. Ji, Y. Jiang, W. Zhao, Q. Chen, and A. Yang, "Sensorless control of linear vernier permanent-magnet motor based on improved mover flux observer," IEEE Transactions on Power Electronics, vol. 35, no. 4, pp. 3869-3877, apr 2020.

[89] Y. Zhang, Z. Yin, F. Gao, and J. Liu, "Research on anti DC bias and high order harmonics of five order flux observer for IPMSM sensorless drive," IEEE Transactions on Industrial Electronics, pp. 1-1, 2021.

[90] H. Kim, M. C. Harke, and R. D. Lorenz, "Sensorless control of interior permanent-magnet machine drives with zero-phase lag position estimation," IEEE Transactions on Industry Applications, vol. 39, no. 6 , pp. 1726-1733, 2003

[91] L. Qu, W. Qiao, and L. Qu, "An enhanced linear active disturbance rejection rotor position sensorless control for permanent magnet synchronous motors," IEEE Transactions on Power Electronics, vol. 35 , no. 6, pp. 6175-6184, jun 2020 .

[92] S. Morimoto, K. Kawamoto, M. Sanada, and Y. Takeda, "Sensorless control strategy for salient-pole pmsm based on extended emf in rotating reference frame," IEEE transactions on industry applications, vol. 38, no. 4, pp. 1054-1061, 2002.

[93] Y. Wang, Y. Xu, and J. Zou, "Sliding-mode sensorless control of pmsm with inverter nonlinearity compensation," IEEE Transactions on Power Electronics, vol. 34, no. 10, pp. 10206-10220, Oct 2019.

[94] J. Zhang, J. Chai, X. Sun, and H. Lu, "An improved voltage model integral algorithm of induction motors based on the orthogonality between back emf and flux," Transactions of China Electrotechnical Society, vol. 29, no. 3, pp. 41-49, 2014.

[95] D. Stojić, M. Milinković, S. Veinović, and I. Klasnić, "Improved stator flux estimator for speed sensorless induction motor drives," IEEE Transactions on Power Electronics, vol. 30, no. 4, pp. 2363-2371, April 2015.

[96] C. Schauder, "Adaptive speed identification for vector control of induction motors without rotational transducers," Industry applications, IEEE Transactions on, vol. 28, no. 5, pp. 1054-1061, 1992.

[97] K. Hurst, T. Habetler, G. Griva, and F. Profumo, "Zero-speed tacholess IM torque control: simply a matter of stator voltage integration," IEEE Transactions on Industry Applications, vol. 34, no. 4, pp. 790-795, 1998

[98] M.-H. Shin, D.-S. Hyun, S.-B. Cho, and S.-Y. Choe, "An improved stator flux estimation for speed sensorless stator flux orientation control of induction motors," IEEE Transactions on Power Electronics, vol. 15, no. 2, pp. 312-318, Mar 2000.

[99] N. R. N. Idris and A. H. M. Yatim, "An improved stator flux estimation in steady-state operation for direct torque control of induction machines," IEEE Transactions on Industry Applications, vol. 38, no. 1, pp. 110-116, Jan 2002.
[100] M. Hinkkanen and J. Luomi, "Modified integrator for voltage model flux estimation of induction motors," IEEE Transactions on Industrial Electronics, vol. 50, no. 4, pp. 818-820, aug 2003.

[101] M. Comanescu and L. Xu, "An improved flux observer based on PLL frequency estimator for sensorless vector control of induction motors," IEEE Transactions on Industrial Electronics, vol. 53, no. 1, pp. 50-56, feb 2006.

[102] G.-R. Chen, J.-Y. Chen, and S.-C. Yang, "Implementation issues of flux linkage estimation on permanent magnet machine position sensorless drive at low speed," IEEE Access, vol. 7, pp. 164641-164 649, 2019.

[103] M. Rahman, M. Haque, L. Tang, and L. Zhong, "Problems associated with the direct torque control of an interior permanent-magnet synchronous motor drive and their remedies," IEEE Transactions on Industrial Electronics, vol. 51, no. 4, pp. 799-809, aug 2004.

[104] B. $\mathrm{Li}$ and $\mathrm{L}$. Li, "New integration algorithms for flux estimation of AC machines," in 2011 International Conference on Electrical Machines and Systems. IEEE, aug 2011.

[105] J. Chen and J. Huang, "Alternative solution regarding problems of adaptive observer compensating parameters uncertainties for sensorless induction motor drives," IEEE Transactions on Industrial Electronics, vol. 67 , no. 7, pp. 5879-5888, July 2020 .

[106] F.-J. Lin, R.-J. Wai, and P.-C. Lin, "Robust speed sensorless induction motor drive," IEEE Transactions on Aerospace and Electronic Systems, vol. 35, no. 2, pp. 566-578, apr 1999.

[107] G. Edelbaher, K. Jezernik, and E. Urlep, "Low-speed sensorless control of induction machine," IEEE Transactions on Industrial Electronics, vol. 53, no. 1, pp. 120-129, feb 2006.

[108] C. Lascu, I. Boldea, and F. Blaabjerg, "Comparative study of adaptive and inherently sensorless observers for variable-speed induction-motor drives," IEEE Transactions on Industrial Electronics, vol. 53, no. 1, pp. 57-65, feb 2006.

[109] Z. Zhang, H. Xu, L. Xu, and L. Heilman, "Sensorless direct fieldoriented control of three-phase induction motors based on "sliding mode" for washing-machine drive applications," IEEE Transactions on Industry Applications, vol. 42, no. 3, pp. 694-701, may 2006.

[110] Y. Yoon, S. Sul, S. Morimoto, and K. Ide, "High-bandwidth sensorless algorithm for ac machines based on square-wave-type voltage injection," IEEE Transactions on Industry Applications, vol. 47, no. 3, pp. 1361-1370, May 2011.

[111] L. Harnefors and H.-P. Nee, "A general algorithm for speed and position estimation of ac motors," IEEE Transactions on Industrial Electronics, vol. 47, no. 1, pp. 77-83, 2000.

[112] R. Lorenz and K. Van Patten, "High-resolution velocity estimation for all-digital, ac servo drives," IEEE Transactions on Industry Applications, vol. 27, no. 4, pp. 701-705, 1991.

[113] P. Vas, Sensorless vector and direct torque control. Oxford University Press, USA, 1998.

[114] T. Zhang, Z. Xu, J. Li, H. Zhang, and C. Gerada, "A third-order supertwisting extended state observer for dynamic performance enhancement of sensorless IPMSM drives," IEEE Transactions on Industrial Electronics, vol. 67, no. 7, pp. 5948-5958, jul 2020.

[115] T. Zhang, Z. Xu, and C. Gerada, "A nonlinear extended state observer for sensorless IPMSM drives with optimized gains," IEEE Transactions on Industry Applications, vol. 56, no. 2, pp. 1485-1494, mar 2020.

[116] Z. Xu, T. Zhang, Y. Bao, H. Zhang, and C. Gerada, "A nonlinear extended state observer for rotor position and speed estimation for sensorless IPMSM drives," IEEE Transactions on Power Electronics, vol. 35, no. 1, pp. 733-743, jan 2020.

[117] M. Preindl and E. Schaltz, "Sensorless model predictive direct current control using novel second-order PLL observer for PMSM drive systems," IEEE Transactions on Industrial Electronics, vol. 58, no. 9, pp. 4087-4095, sep 2011.

[118] H. Tajima, Y. Matsumoto, and H. Umida, "Speed sensorless vector control method for an industrial drive system," IEEJ Transactions on Industry Applications, vol. 116, no. 11, pp. 1103-1109, 1996.

[119] L. Zhao, J. Huang, J. Chen, and M. Ye, "A parallel speed and rotor time constant identification scheme for indirect field oriented induction motor drives," IEEE Transactions on Power Electronics, vol. 31, no. 9, pp. 6494-6503, Sept 2016.

[120] K. Bradley, H Guldemir, "The effect of rotor design on rotor slot harmonics in induction machines," Electric Power Components and Systems, vol. 29, no. 9, pp. 771-788, 2001.

[121] M. Ishida and K. Iwata, "A new slip frequncy detector of an induction motor utilizing rotor slot harmonics," IEEE Transactions on Industry Applications, vol. IA-20, no. 3, pp. 575-582, 1984.

[122] K. Hurst and T. Habetler, "A comparison of spectrum estimation techniques for sensorless speed detection in induction machines," IEEE 
Transactions on Industry Applications, vol. 33, no. 4, pp. 898-905, 1997.

[123] J. S. Lee, R. D. Lorenz, and M. A. Valenzuela, "Time-optimal and loss-minimizing deadbeat-direct torque and flux control for interior permanent-magnet synchronous machines," IEEE Transactions on Industry Applications, vol. 50, no. 3, pp. 1880-1890, 2014.

[124] L. Harnefors, "Instability phenomena and remedies in sensorless indirect field oriented control," Power Electronics, IEEE Transactions on, vol. 15, no. 4, pp. 733-743, Jul 2000.

[125] H. Rehman, A. Derdiyok, M. Guven, and L. Xu, "A new current model flux observer for wide speed range sensorless control of an induction machine," IEEE Transactions on Power Electronics, vol. 17, no. 6, pp. 1041-1048, nov 2002.

[126] A. Derdiyok, M. Guven, H. Rehman, N. Inanc, and L. Xu, "Design and implementation of a new sliding-mode observer for speed-sensorless control of induction machine," IEEE Transactions on Industrial Electronics, vol. 49, no. 5, pp. 1177-1182, oct 2002.

[127] M. Morawiec and A. Lewicki, "Speed observer structure of induction machine based on sliding super-twisting and backstepping techniques," IEEE Transactions on Industrial Informatics, vol. 17, no. 2, pp. 11221131, feb 2021.

[128] C. Du, Z. Yin, J. Liu, Y. Zhang, and X. Sun, "A speed estimation method for induction motors based on active disturbance rejection observer," IEEE Transactions on Power Electronics, vol. 35, no. 8, pp. 8429-8442, aug 2020 .

[129] M. Comanescu and L. Xu, "Sliding-mode MRAS speed estimators for sensorless vector control of induction machine," IEEE Transactions on Industrial Electronics, vol. 53, no. 1, pp. 146-153, feb 2006.

[130] C. Lascu, I. Boldea, and F. Blaabjerg, "A class of speed-sensorless sliding-mode observers for high-performance induction motor drives," IEEE Transactions on Industrial Electronics, vol. 56, no. 9, pp. 33943403, sep 2009.

[131] G. Yang and T. H. Chin, "Adaptive-speed identification scheme for a vector-controlled speed sensorless inverter-induction motor drive," IEEE Transactions on Industry Applications, vol. 29, no. 4, pp. 820825, Jul 1993.

[132] G. Yang and T.-H. Chin, "Hyperstability of the full-order observer for vector-controlled induction motor drive without speed sensor," Elect. Eng. Jpn., vol. 113, p. 109-118, 1993.

[133] K. Kubota and K. Matsuse, "Speed sensorless field-oriented control of induction motor with rotor resistance adaptation," Industry Applications, IEEE Transactions on, vol. 30, no. 5, pp. 1219-1224, Sep 1994.

[134] H. Kubota, I. Sato, Y. Tamura, K. Matsuse, H. Ohta, and Y. Hori, "Regenerating-mode low-speed operation of sensorless induction motor drive with adaptive observer," IEEE Transactions on Industry Applications, vol. 38, no. 4, pp. 1081-1086, Jul 2002.

[135] H. Tajima, G. Guidi, and H. Umida, "Consideration about problems and solutions of speed estimation method and parameter tuning for speed-sensorless vector control of induction motor drives," Industry Applications, IEEE Transactions on, vol. 38, no. 5, pp. 1282-1289, 2002.

[136] M. S. Zaky, M. k. Metwally, H. Azazi, and S. Deraz, "A new adaptive smo for speed estimation of sensorless induction motor drives at zero and very low frequencies," IEEE Transactions on Industrial Electronics, vol. PP, no. 99, pp. 1-1, 2018.

[137] C. Luo, B. Wang, Y. Yu, Y. Zhu, and D. Xu, "Enhanced low frequency ride-through for speed-sensorless induction motor drives with adaptive observable margin," IEEE Transactions on Industrial Electronics, pp. $1-1,2020$.

[138] N.-D. Nguyen, N. N. N. Nam, C. Yoon, and Y. I. Lee, "Speed sensorless model predictive torque control of induction motors using a modified adaptive full-order observer," IEEE Transactions on Industrial Electronics, pp. 1-1, 2021.

[139] X. Zhang, "Sensorless induction motor drive using indirect vector controller and sliding-mode observer for electric vehicles," IEEE Transactions on Vehicular Technology, vol. 62, no. 7, pp. 3010-3018, sep 2013.

[140] S. Suwankawin and S. Sangwongwanich, "Design strategy of an adaptive full-order observer for speed-sensorless induction-motor drivestracking performance and stabilization," IEEE Transactions on Industrial Electronics, vol. 53, no. 1, pp. 96-119, Feb 2006.

[141] E. Etien, C. Chaigne, and N. Bensiali, "On the stability of full adaptive observer for induction motor in regenerating mode," IEEE Transactions on Industrial Electronics, vol. 57, no. 5, pp. 1599-1608, May 2010.

[142] S. Sangwongwanich, S. Suwankawin, S. Po-ngam, and S. Koonlaboon, "A unified speed estimation design framework for sensorless ac motor drives based on positive-real property," in 2007 Power Conversion Conference - Nagoya, April 2007, pp. 1111-1118.

[143] W. Sun, Y. Yu, G. Wang, B. Li, and D. Xu, "Design method of adaptive full order observer with or without estimated flux error in speed estimation algorithm," IEEE Transactions on Power Electronics, vol. 31, no. 3, pp. 2609-2626, March 2016.

[144] M. Hinkkanen and J. Luomi, "Stabilization of regenerating-mode operation in sensorless induction motor drives by full-order flux observer design," IEEE Transactions on Industrial Electronics, vol. 51, no. 6, pp. 1318-1328, Dec 2004.

[145] L. Harnefors, "Globally stable speed-adaptive observers for sensorless induction motor drives," IEEE Transactions on Industrial Electronics, vol. 54, no. 2, pp. 1243-1245, April 2007.

[146] P. Kudva and K. S. Narendra, "Synthesis of an adaptive observer using lyapunov's direct method," International Journal of Control, vol. 18 , no. 6 , pp. 1201-1210, 1973.

[147] R. Marino and P. Tomei, "Global adaptive observers for nonlinear systems via filtered transformations," IEEE Transactions on Automatic Control, vol. 37, no. 8, pp. 1239-1245, Aug 1992.

[148] Q. Zhang, "Adaptive observer for multiple-input-multiple-output (mimo) linear time-varying systems," IEEE Transactions on Automatic Control, vol. 47, no. 3, pp. 525-529, Mar 2002.

[149] M. Farza, M. M'Saad, T. Maatoug, and M. Kamoun, "Adaptive observers for nonlinearly parameterized class of nonlinear systems," Automatica, vol. 45, no. 10, pp. 2292-2299, 2009.

[150] M. Farza, M. M’Saad, T. Ménard, A. Ltaief, and T. Maatoug, "Adaptive observer design for a class of nonlinear systems. application to speed sensorless induction motor," Automatica, vol. 90, pp. 239-247, 2018.

[151] R. Marino and P. Tomei, Nonlinear control design: geometric, adaptive and robust. Prentice Hall International (UK) Ltd., 1995.

[152] R. Marino, P. Tomei, and C. M. Verrelli, Induction motor control design. Springer London, 2010.

[153] Y. Zheng and K. A. Loparo, "Adaptive flux and speed estimation for induction motors," in Proceedings of the 1999 American Control Conference (Cat. No. 99CH36251), vol. 4, 1999, pp. 2521-2525 vol.4.

[154] A. Dib, M. Farza, M. M'Saad, P. Dorleans, and J.-F. Massieu, "High gain observer for sensorless induction motor," IFAC Proceedings Volumes, vol. 44, no. 1, pp. 674-679, 2011.

[155] J. Chen and J. Huang, "Globally stable speed-adaptive observer with auxiliary states for sensorless induction motor drives," IEEE Transactions on Power Electronics, vol. 34, no. 1, pp. 33-39, Jan 2019.

[156] J. Chen, J. Huang, and Y. Sun, "Resistances and speed estimation in sensorless induction motor drives using a model with known regressors," IEEE Transactions on Industrial Electronics, vol. 66, no. 4 , pp. 2659-2667, April 2019.

[157] J. Chen and J. Huang, "Application of adaptive observer to sensorless induction motor via parameter-dependent transformation," IEEE Transactions on Control Systems Technology, vol. 27, no. 6, pp. 2630-2637, Nov 2019.

[158] H. Tajima and Y. Hori, "Speed sensorless field-orientation control of the induction machine," Industry Applications, IEEE Transactions on, vol. 29, no. 1, pp. 175-180, 1993.

[159] M. Amin, G. A. A. Aziz, and J. Durkin, "A robust simplified dynamic observer-based backstepping control of six-phase induction motor for marine vessels applications," in 2019 IEEE Industry Applications Society Annual Meeting. IEEE, sep 2019.

[160] J. Chen and J. Huang, "Online decoupled stator and rotor resistances adaptation for speed sensorless induction motor drives by a timedivision approach," IEEE Transactions on Power Electronics, vol. 32, no. 6, pp. 4587-4599, June 2017.

[161] M. H. Holakooie, M. Ojaghi, and A. Taheri, "Modified DTC of a sixphase induction motor with a second-order sliding-mode MRAS-based speed estimator," IEEE Transactions on Power Electronics, vol. 34, no. 1 , pp. 600-611, jan 2019

[162] M. Korzonek, G. Tarchala, and T. Orlowska-Kowalska, "A review on mras-type speed estimators for reliable and efficient induction motor drives," ISA transactions, 2019.

[163] P. L. Jansen and R. D. Lorenz, "Transducerless field orientation concepts employing saturation-induced saliencies in induction machines," IEEE Transactions on Industry Applications, vol. 32, no. 6, pp. 13801393, Nov 1996.

[164] J. Han, Active disturbance rejection control technique-the technique for estimating and compensating the uncertainties. National Defense Industry Press, Beijing, 2008.

[165] H. Sira-Ramírez, A. Luviano-Juárez, M. Ramírez-Neria, and E. W. Zurita-Bustamante, Active disturbance rejection control of dynamic systems: a flatness based approach. Butterworth-Heinemann, 2018. 
[166] Y. Zuo, J. Chen, X. Zhu, and C. H. T. Lee, "Different active disturbance rejection controllers based on the same order gpi observer," IEEE Transactions on Industrial Electronics, 2021.

[167] A. A. Godbole, J. P. Kolhe, and S. E. Talole, "Performance analysis of generalized extended state observer in tackling sinusoidal disturbances," IEEE Transactions on Control Systems Technology, vol. 21, no. 6, pp. 2212-2223, nov 2013.

\section{CONTEnTs}

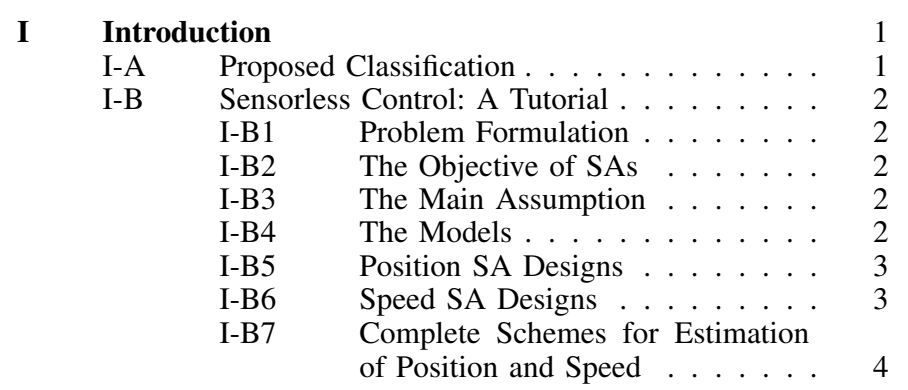

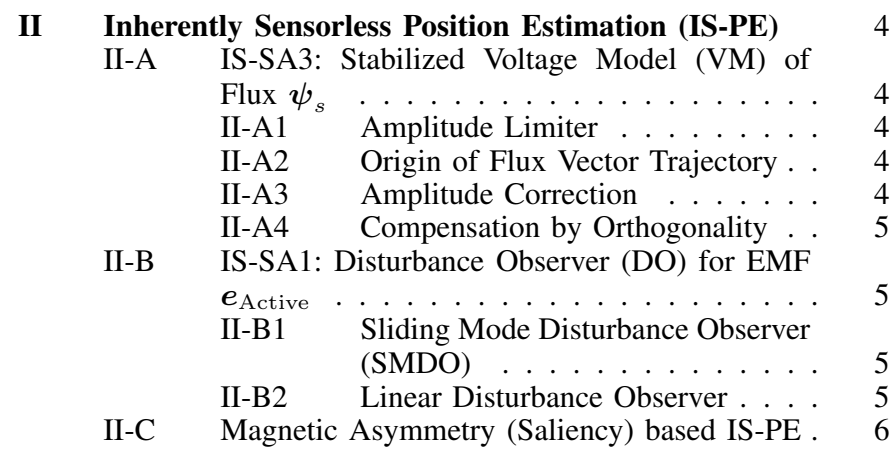

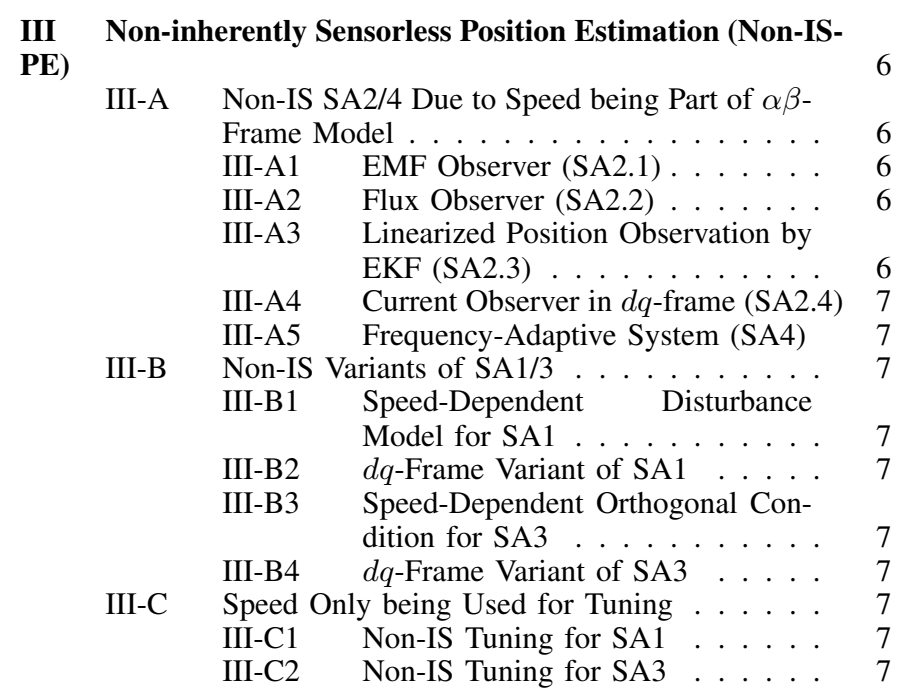

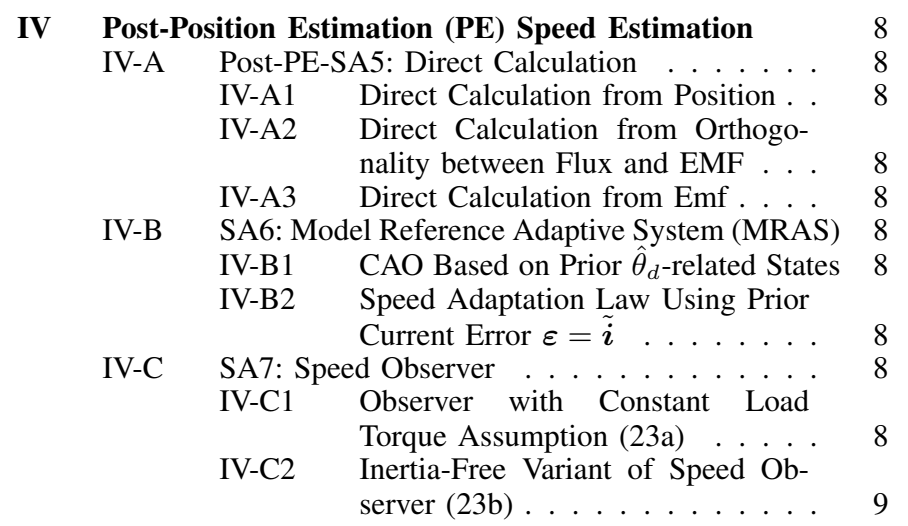

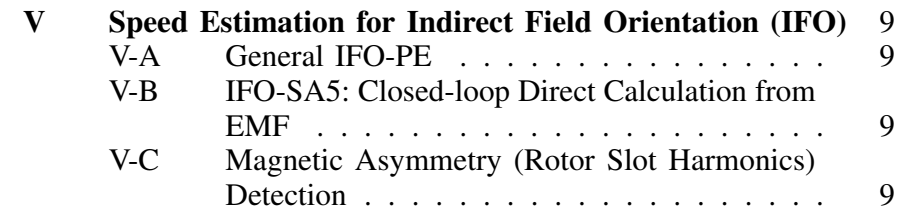

VI Lose the Constant $K$ active Assumption VI-A \begin{tabular}{l} 
Compensation for Time-Varying $K_{\text {Active }}$ in \\
\hline
\end{tabular}

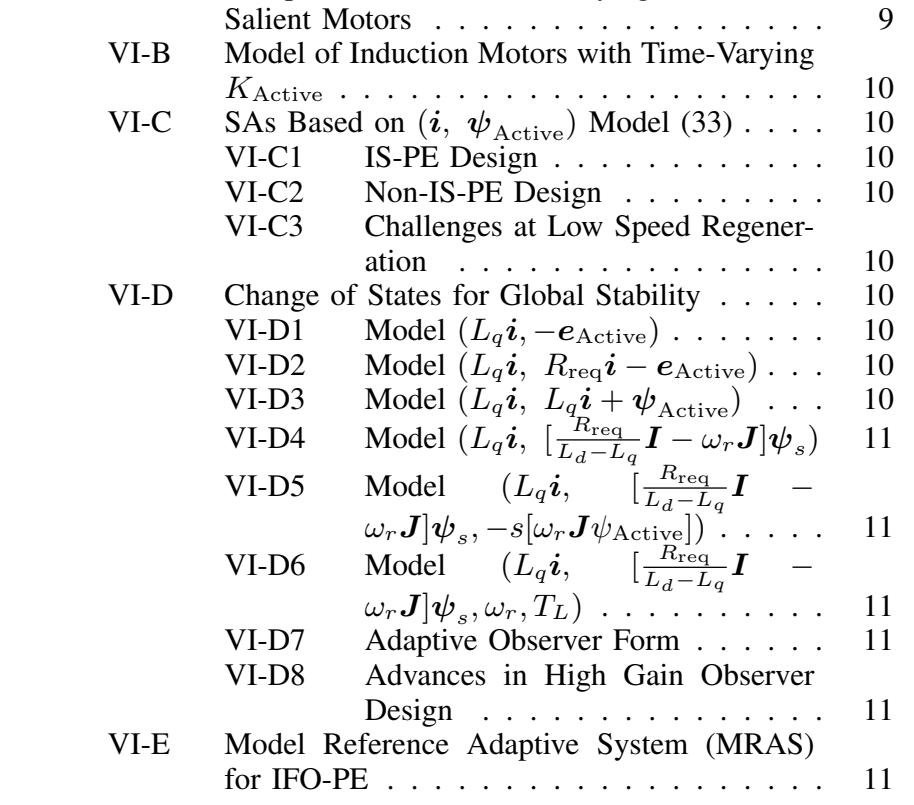

VII Concluding Remarks

Appendix A: Position Estimator Design Basics

Appendix B: Speed Estimator Design Basics

References 